\title{
Boosted Fast Flux Loop Final Report
}

September 2009

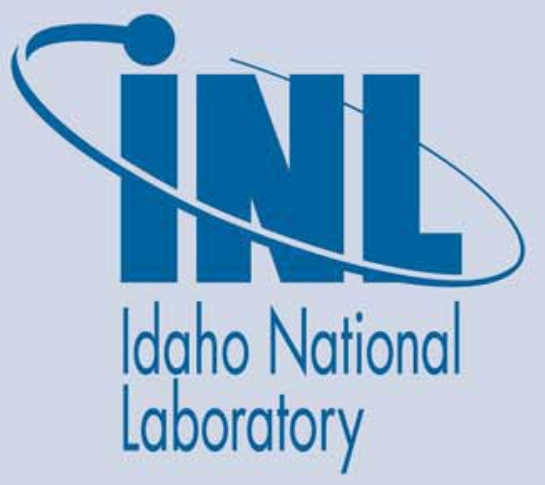

The INL is a U.S. Department of Energy National Laboratory operated by Battelle Energy Alliance 
INL/EXT-09-16413

\title{
Boosted Fast Flux Loop Final Report
}

September 2009

\author{
Idaho National Laboratory \\ Fuels Performance and Design Department \\ Idaho Falls, Idaho 83415 \\ http://www.inl.gov
}

Prepared for the U.S. Department of Energy Office of Nuclear Energy Under DOE Idaho Operations Office

Contract DE-AC07-05ID14517 


\section{BOOSTED FAST FLUX LOOP INL PROJECT TEAM}

Richard Ambrosek*
John Baker
Scott Barrie
Tom Berti
Lori Braase
Mike Carboneau*
Peter Castle*
John Chapman
Nathan Chipman*
Kevin Clayton
Glenn Clemons
Robert Evans*
Jim Fisher*
Hans Gougar
Marylou Dunzik-Gougar
Jim Graham
Donna Post Guillen
Lawrnel Harrison
Ed Harvego
Steve Hayes
Max Heberling*
Dave Herrin
J. Keith Jewell
Soli Khericha
Darrell Knudson
Glen Longhurst*
Frances Marshall
George Marts
Kathy McBride
Kathryn McCarthy
Tom McDonald
Travis Mitchell
Wynn Monk
Nathan Oldham
Jim Parry
Keith Penny
Bubba Ricker
Wayne Ridgway
Adam Robinson
Bob Roesener
Rhonda Rohe
Paul Roth
Mark Russell

Thermal Analysis

Cost Estimating

Booster Fuel Mechanical Design

Instrumentation \& Controls

Project Support

Fuel Design Lead

Fuel Life Cycle Management

Nuclear Engineering

Fuel Life Cycle Management Lead

Loop Design Technical Lead

Procurement

Instrumentation \& Controls

Thermal Hydraulics

Program Management

ISU - Alternatives Analysis

Environmental/NEPA

Thermal Analysis

Mechanical Design - Gas Control System

Analytical Code Qualification

Fuel Design

Reactor Operations

Federal Project Director

Reactor Physics

Requirements Assist. Lead

Capsule Design

Requirements Definition Lead

Program Management

Instrumentation \& Controls

Fuels Development

Manager, Advanced Nuclear Energy Systems Integration

Facility Preparations and Mechanical Design

Program Controls

ATR Feasibility Lead

Drafting

Neutronics

ATR Engineering Management

Drafting

Project Manager

Post-Irradiation Examination

Transportation Issues

Waste Generator Services

ATR Core Neutronics

Structural/Mechanical Engineering 


$\begin{array}{ll}\text { Janis Sherick* } & \text { Project Support Lead } \\ \text { Ali Siahpush } & \text { Alternatives Analysis Coordinator/Thermal Hydraulics } \\ \text { Bill Skerjanc } & \text { ISU - Alternatives Analysis } \\ \text { W. Ken Sowder } & \text { Quality Assurance } \\ \text { Dave Stites } & \text { Mechanical design - In-Core Hardware } \\ \text { Brad Stockton } & \text { Safety Analysis } \\ \text { Eric Tomberlin } & \text { Electrical Design - Gas Control System } \\ \text { Terry Tomberlin } & \text { Safety Analysis } \\ \text { Robert Turk } & \text { Systems Engineering } \\ \text { Craig Tyler } & \text { Irradiation Experiment Engineer } \\ \text { Dan Wachs } & \text { Fuels Development } \\ \text { Steve Wagoner } & \text { Safety Analysis } \\ \text { Chuck Wemple* } & \text { Neutronics Lead } \\ \text { Amy Yarger* } & \text { Administration } \\ & \end{array}$




\section{ABSTRACT}

The Boosted Fast Flux Loop (BFFL) project was initiated to determine basic feasibility of designing, constructing, and installing in a host irradiation facility, an experimental vehicle that can replicate with reasonable fidelity the fast-flux test environment needed for fuels and materials irradiation testing for advanced reactor concepts. Originally called the Gas Test Loop (GTL) project, the activity included (1) determination of requirements that must be met for the GTL to be responsive to potential users, (2) a survey of nuclear facilities that may successfully host the GTL, (3) conceptualizing designs for hardware that can support the needed environments for neutron flux intensity and energy spectrum, atmosphere, flow, etc. needed by the experimenters, and (4) examining other aspects of such a system, such as waste generation and disposal, environmental concerns, needs for additional infrastructure, and requirements for interfacing with the host facility. The project received funding for conceptual design, and a Conceptual Design Plan (PLN-1801) was approved in September 2004. The objective at that time was to submit an application for CD-1 by June 30, 2005. As project complexity increased and projected costs grew, it became apparent that the project was not ready for CD-1 in FY- 05 . Rev. 1 to PLN 1801 became effective July 28, 2005. The revision was based on the need for reduction in technical risk in a number of areas before it would be appropriate to apply for the $\mathrm{CD}-1$. The revised plan included requesting an interim decision, termed CD-1A, that had objectives of " establishing the site for the project at the Advanced Test Reactor (ATR) at the Idaho National Laboratory (INL), deferring the CD-1 application, and authorizing a research program that would resolve the most pressing technical questions regarding GTL feasibility, including issues relating to the use of booster fuel in the ATR. Those recommendations were accepted on September 13, 2005. Major research tasks arising from that action were (1) hydraulic testing to establish flow conditions through the booster fuel, (2) mini-plate irradiation tests and post-irradiation examination to alleviate concerns over corrosion at the high heat fluxes planned, (3) development and demonstration of booster fuel fabrication techniques, and (4) a review of the impact of the GTL on the ATR safety basis. In an attempt to save substantially in project costs, a revised cooling concept for the apparatus was conceptualized, which resulted in renaming the project to the BFFL. Before the subsequent CD-1 approval request could be made, a decision was made in April 2006 that further funding for the project would be suspended.

Since that time, remaining funds have been used to prepare and irradiate mini-plates of the proposed booster fuel needed to achieve the required neutron flux levels, a necessary step if the concept is to be advanced further. This irradiation test (designated GLT-1) of mini-plates was completed, and their postirradiation examination indicated that fuel performance at, and even significantly above, the peak operating conditions predicted for the BFFL booster fuel plates was acceptable. The current baseline design is for a set of three test positions inside an in-pile tube with a thermal neutron absorber and heat sink made of aluminum mixed with hafnium. Gas gap conductance temperature control may be used around the experiment positions, which will be mainly encapsulated experiments, though flow-through experiments are also possible. Operating the ATR at power levels needed to achieve the required fast flux will result in an estimated increase in ATR fuel consumption between 15 and 20\% above present rates and a reduction in the time between fuel replacements. Flux traps adjacent to the BFFL position will have increased power levels above their current ones, but the other main lobes of the reactor can operate at their traditional power levels. A life cycle management plan was initiated for the booster fuel, 
operational adjustments for fuel and experiment handling, and the necessary revisions to the ATR safety documentation. Preliminary safety analyses conducted have indicted safe operation of the ATR with the GTL under normal, abnormal, and postulated accident conditions. More comprehensive analyses are needed. 


\section{CONTENTS}

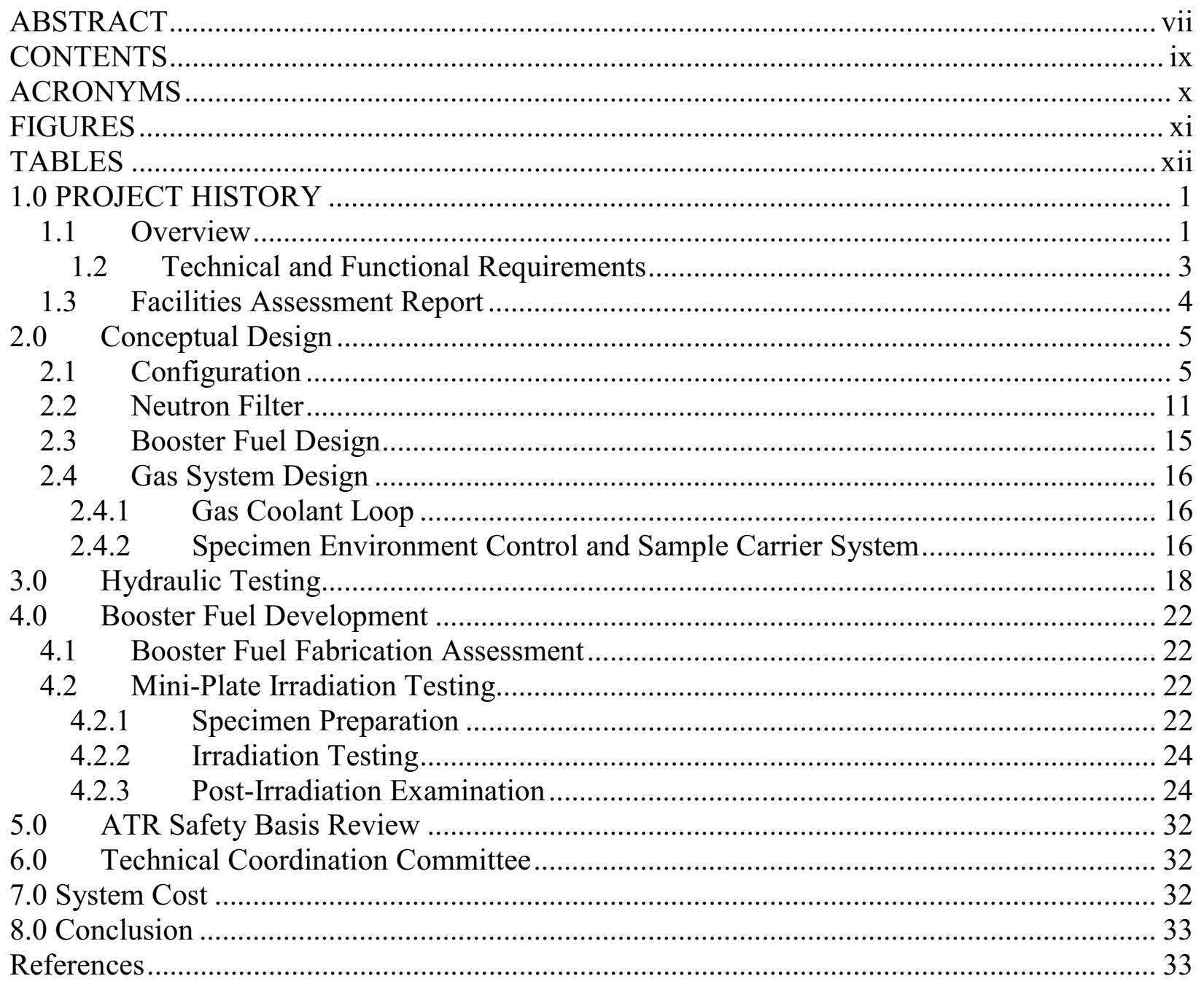




\section{ACRONYMS}

$\begin{array}{ll}\text { ATR } & \text { Advanced Test Reactor } \\ \text { BFFL } & \text { Boosted Fast Flux Loop } \\ \text { CD-0 } & \text { Critical Decision 0 (Approve Mission Need) } \\ \text { CD-1 } & \text { Critical Decision 1 (Approve Preliminary Baseline Range) } \\ \text { DOE } & \text { U. S. Department of Energy } \\ \text { GTL } & \text { Gas Test Loop } \\ \text { HEU } & \text { highly enriched uranium } \\ \text { HFEF } & \text { Hot Fuels Examination Facility } \\ \text { HFIR } & \text { High Flux Isotope Reactor } \\ \text { INL } & \text { Idaho National Laboratory } \\ \text { MTS } & \text { Materials Test Station } \\ \text { NASA } & \text { National Aeronautics and Space Administration } \\ \text { NGNP } & \text { Next Generation Nuclear Plant } \\ \text { PIE } & \text { post-irradiation examination }\end{array}$




\section{FIGURES}

Figure 1. Booster fuel and initial hafnium filter designs with a proposed test train configuration. This configuration was gas-cooled.

Figure 2. ATR Lobe fuel configuration with detail at the top of the core, showing ATR driver fuel and booster fuel...

Figure 3. Booster fuel element configuration............................................................. 10

Figure 4. Positioning of the GTL assembly in the ATR reactor vessel.................................. 11

Figure 5 Second design iteration on arrangement of components in the GTL...................... 12

Figure 6. Dispersed thermal neutron absorber concept................................................. 14

Figure 7. Fast-to-thermal ratios and fast flux attainable with the dispersed thermal neutron

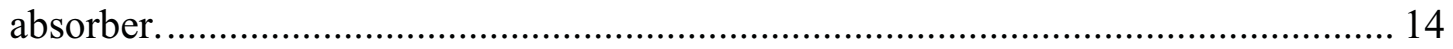

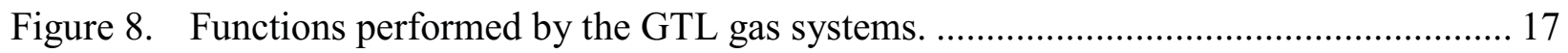

Figure 9. Schematic (a) and implementation (b) of the hydraulic test loop used for measuring the flow coefficient of the proposed BFFL booster fuel....................................... 18

Figure 10. Model booster fuel assemblies. The second from the left has brackets (inset) to hold the Pitot tubes used to measure flow velocities.

Figure 11. View of the lower support ring in the model flow baffle assembly from below with the model booster fuel elements installed.

Figure 12. Flow coefficients derived from flow and pressure-drop data for the model booster fuel elements. Zones are (1) upper end cap, (2) inside innermost fuel plate, (3) between innermost fuel plate and middle fuel plate, (3) between middle fuel plate and outermost fuel plate, (4) outside outermost fuel plate, (5) lower end cap, and (6) flow distribution tank

Figure 13. Composite plot of spectral density for the dynamic pressures recorded. Peaks in the 900- to $1400-\mathrm{Hz}$ range were believed generated by vortex shedding over fuel plate leading edges.

Figure 14. Elements of mini-plate fabrication: (a) fuel meat compact forming die, (b) Compact placement in frame before welding of cladding plates, and (c) Rolled plate with 6 mini-plates before cutting.

Figure 15. Booster fuel mini-plate dimensions and mounting configuration

Figure 16. Visual inspection photographs of sample US16DM (a) front, and (b) back, which was irradiated in the $\mathrm{C} 2$ position.

Figure 17. Locations of pre-irradiation thickness measurements on booster fuel mini-plate specimens.

Figure 18. Locations for surface oxide measurements on the mini-plate specimens................. 28

Figure 19. Metallographic montage of cross section images for sample US16DM................... 30 
Figure 20. Metallographic images of specimen US16DM (a) fuel meat at low-power edge, (b) fuel meat at high-power edge, (c) oxide film interface at low-power edge, and (d) oxide film interface at high-power edge.

Figure 21. Metallographic montage of cross section images for sample UA01FS.

Figure 22. Metallographic images of specimen UA01FS (a) fuel meat at low-power edge, (b) fuel meat at high-power edge, (c) oxide film interface at low-power edge, and (d) oxide film interface at high-power edge.

\section{TABLES}

Table 1. Summary of features required by the Gas Test Loop. The requirements shown are those

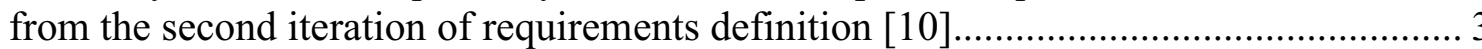

Table 2. Comparison of candidate alternative irradiation facilities to the Required technical and functional requirements of the proposed ATR GTL. ................................................. 6

Table 3. Comparison of Candidate Alternative Irradiation Facilities to the Desired Technical and Functional Requirements of the Proposed GTL.

Table 4. Matrix of specimen characteristics for GTL mini-plates irradiated in the ATR South Flux Trap. 25

Table 5.Pre-irradiation thickness measurements ( $\mathrm{mm}$ ) on specimen US16DM.

Table 6. Thickness measurement results (mm) for sample US16DM at the locations indicated.. 27

Table 7. Results of mini-plate surface oxide measurements. Thicknesses are in micrometers..... 28 


\subsection{PROJECT HISTORY}

\subsection{Overview}

In 2004, the Nuclear Energy Program within the U.S. Department of Energy (DOE-NE) identified the need for irradiation testing of nuclear fuels and materials primarily in support of the Generation IV and Advanced Fuel Cycle Initiative programs. This need was documented and approved in the Justification of Mission Need for the Gas Test Loop [1]. That action constituted Critical Decision 0 (Approve Mission Need) and allowed the Gas Test Loop (GTL) Project to proceed into the conceptual design phase, per DOE Order 413.3, Program and Project Management for the Acquisition of Capital Assets.

The project received funding for conceptual design, and a Conceptual Design Plan (PLN-1801) was approved in September 2004. The objective at that time was to submit an application for Critical Decision 1 (Approve Preliminary Baseline Range) by June 30, 2005. Technical and functional requirements were generated [2], and a facilities alternatives assessment study [3] was undertaken to determine which of the possible available nuclear facilities would be the best site for the GTL. Conceptual design began almost at once. Formal project reviews were held at the $30 \%, 70 \%$, and $100 \%$ completion points in the conceptual design activity [4 - 6]. A Technical Coordinating Committee was assembled consisting of technical experts from Argonne National Laboratory, Oak Ridge National Laboratory, the University of Wisconsin, the University of Florida, and from BWXT. Other members were from DOE Headquarters and DOE-ID. This committee served as an advisory board to review and comment on planned design and development activities of the GTL.

As project complexity increased and projected costs grew, it became apparent that the project was not ready for CD-1 in FY-05. Rev. 1 to PLN 1801 became effective July 28, 2005. The revision was based on the need for reduction in technical risk in a number of areas before it would be appropriate to apply for the CD-1. The revised plan included requesting an interim decision, termed CD-1A, that had two major objectives: (1) establishing the site for the project at the Advanced Test Reactor (ATR) at the Idaho National Laboratory (INL) in accordance with the findings of the facilities assessment report [3], and (2) deferring the CD-1 application and authorizing a research program that would resolve the most pressing technical questions regarding GTL feasibility, including issues relating to the use of booster fuel in the ATR [7]. Successful completion of these interim activities, during what was termed Advanced Conceptual Design, was intended to resolve those issues needed to request CD-1 approval. It was planned that the request for CD-1 would be made in the third or fourth quarter of FY-2007. The continued research activities included hydraulic testing; booster fuel mini-plate specimen fabrication, irradiation testing, and post-irradiation examination (PIE); booster fuel fabrication technology development; and a review of the ATR safety basis.

About mid-year in FY-2006, it became apparent that support for the project was waning. Even though there were advocates at various levels within the DOE, the leadership of the Next Generation Nuclear Plant project, anticipated to be the primary customer for whom the BFFL was being developed, determined that continued funding for the project was not in their best interest. Accordingly, many of the project activities planned or in progress were curtailed. It was 
decided at that time that most of the funds remaining in the project would be best used in executing the booster fuel mini-plate irradiation testing and PIE since that would answer the most significant technical feasibility questions for the project. When it became apparent that the flux power swings in the Large B position planned for the irradiation testing of the booster fuel mini-plates would be too severe for experiment safety and it was discovered that manufacturing defects in the mini-plate specimens arising from a rolling mill failure rendered some of the samples unsuitable for the test, a decision was made to change the irradiation position to the South Flux Trap. Sufficient funds were made available from the FY-06 budget allocation to pursue that objective.

Early in May 2007, an investigation was begun to search for an alternative cooling approach for the GTL. The original design had called for the experiment chambers to be cooled by pressurized helium. The preliminary cost estimate for the helium cooling system was of order $\$ 50 \mathrm{M}$. A focus group convened on May 7, 2007, and the possibility of having the hafnium thermal neutron absorber dispersed in an aluminum heat transfer medium was conceived. Several other approaches were considered, but his seemed to have the most merit. The resulting study [8] showed that it was possible to save the project over $\$ 25 \mathrm{M}$ while still achieving the performance criteria. The generation of the new concept for the system begun as the GTL resulted in renaming of the project as the Boosted Fast Flux Loop (BFFL).

In June of 2007, the need for a "Fast Neutron Test Capability" was revisited. The need was found to continue, but a different approach was proposed. A DOE planning document stated,

\begin{abstract}
"No funding was requested for FY08 (FY CY). The original technical approach to address the 2004 mission need was called the Gas Test Loop (GTL). During the conceptual design process, estimated cost escalation and technical issues have led to the GTL option being de-selected. The mission need was reassessed and determined to still remain. The other CD-0 options and a new concept are being developed. This budget request is a result of reaffirming the mission need which will be addressed using an approach different from the GTL. Those options will be developed through conceptual design efforts in FY08 to support a 9/2008 CD-1. CD-1 will select the best technical approach. In FY 2009 the selected option design will be completed and depending on the option, assembly will be commenced after an appropriate performance baseline is established (CD-2) [9].
\end{abstract}

A combined program review involving the BFFL, the Materials Test Station at Los Alamos National Laboratory, and a concept proposed for the High Flux Isotope Reactor at Oak Ridge National Laboratory resulted in funding being provided for the other two approaches but not for the BFFL.

Mini-plate irradiation testing in the South Flux Trap was completed in mid January 2009 and by mid-February, the samples had been transferred to the Hot Fuels Examination Facility (HFEF) at the Materials and Fuels Complex. PIE was completed in June 2009. Investigations included general dimensional checks, gamma scanning, oxide thickness determination, and destructive metallographic examination. The PIE showed the mini-plates in the experiment performed quite well overall. Swelling values were acceptable for the very high fission densities experienced. Oxide layers were acceptable and uniform across the experiment, in spite of the fairly substantial flux gradients seen. Metallography showed no surprises with grain structures that were well behaved. 
The BFFL project was then closed, being held in abeyance until such time as the need for this or a similar capability resurfaces.

\subsection{Technical and Functional Requirements}

The Gas Test Loop (GTL) Project was initiated to develop test assemblies that could be used in an existing irradiation facility to provide the test environments needed by a variety of programs ranging from the Advanced Fuel Cycle Initiative and Generation IV Reactor Program to the proposed NASA Space Nuclear Power program. The range of parameters called for by the various programs that may have made use of the GTL suggested the greatest economy could be achieved by having two implementations of the GTL concept, each adapted to a different kind of testing.

The various reactor programs will have differing needs for environmental parameters. Indeed, the testing for most programs will involve two distinctly different kinds of testing. One addresses the damage and property changes inflicted on fuels and materials by the neutron (and to a less extent gamma) fields under their intended operating conditions. For such tests, neutron flux and energy spectra are highly important. Other tests will be more concerned with the evolution of fission fragments and activation products from fuels and materials and the transport of those materials through the coolant system. There, heating power will be more important than neutron energy. There, too, meaningful representation of the coolant loop with its flows and thermal conditions will be essential.

Requirements thought essential for this suite of missions were documented in Ref. [2]. After working with the project for a year and considering in more realistic terms what the missions would like be and what capabilities could be included, a revised set of requirements was prepared [10]. Table 1 lists the required features the GTL would need to meet the stated objectives of the developmental reactor programs mentioned from this revised requirements list. The values shown there are in many cases extremes and not all requirements would be imposed on each implementation of the GTL system. Testing requirements for the individual programs supported would dictate the specific parameters that must be met in support of that program. The required features listed, where applicable, were considered the minimum acceptable for the GTL. Also listed are desirable features, which would make the GTL more serviceable to users but incorporation of these features were to be determined by cost effectiveness and technical feasibility.

Table 1. Summary of features required by the Gas Test Loop. The requirements shown are those from the second iteration of requirements definition [10].

\begin{tabular}{|l|c|c|c|}
\hline \multicolumn{1}{|c|}{ Parameter } & Required & Desired & Comments \\
\hline Test volume length $(\mathrm{cm})$ & 15.5 & 89 & \\
\hline Test volume diameter $(\mathrm{cm})$ & 2.54 & 5.9 & \\
\hline $\begin{array}{l}\text { Fast flux intensity }\left(\mathrm{n} / \mathrm{cm}^{2} / \mathrm{s},\right. \\
\mathrm{E}>0.1 \mathrm{MeV}, \text { unperturbed) }\end{array}$ & $1.0 \mathrm{E}+15$ & $3.0 \mathrm{E}+15$ & \\
\hline Fast/thermal neutron flux ratio & $>15$ & $>100$ & \\
\hline $\begin{array}{l}\text { Flux uniformity in test space } \\
(\% \text { deviation from mean) }\end{array}$ & \pm 10 & \pm 5 & \\
\hline
\end{tabular}




\begin{tabular}{|c|c|c|c|}
\hline Parameter & Required & Desired & Comments \\
\hline $\begin{array}{l}\text { Temperature at test article } \\
\text { surface }\left({ }^{\circ} \mathrm{C}\right)\end{array}$ & $\begin{array}{c}500 \pm 15 \text { to } 1,100 \\
\pm 20\end{array}$ & $500 \pm 15$ to $1,830 \pm 50$ & $\begin{array}{c}\text { greater margin } \\
\text { for higher } \\
\text { temperatures }\end{array}$ \\
\hline $\begin{array}{l}\text { Maximum test article linear } \\
\text { heat rate }(\mathrm{W} / \mathrm{cm})\end{array}$ & 2,300 & 3,000 & \\
\hline $\begin{array}{l}\text { Maximum total test article } \\
\text { thermal power }(\mathrm{kW})\end{array}$ & 200 & 3,600 & \\
\hline Gas flow to test chamber & $\begin{array}{c}\text { Sufficient for } \\
\text { cooling/monitoring/ } \\
\text { atmospheric control } \\
\text { as needed }\end{array}$ & & $\begin{array}{c}\text { See Section } \\
\text { 3.1.4 of Ref. [] }\end{array}$ \\
\hline \multicolumn{4}{|l|}{ Measurements } \\
\hline Temperature $\left({ }^{\circ} \mathrm{C}\right)$ & $\begin{array}{l}15 \text { Channels } \\
30 \text { to } 1,400\end{array}$ & $\begin{array}{l}30 \text { Channels } \\
30 \text { to } 1,800\end{array}$ & $\begin{array}{c}\text { Higher } \\
\text { temperatures } \\
\text { may be } \\
\text { witnessed by } \\
\text { melt wires }\end{array}$ \\
\hline $\begin{array}{l}\text { Temperature control gas } \\
\text { composition }\end{array}$ & $\begin{array}{c}15 \text { channels } \\
\text { down to } 1 \mathrm{mg} / \mathrm{kg} \\
\pm 3 \%\end{array}$ & $\begin{array}{c}15 \text { channels } \\
\text { down to } 0.1 \mathrm{mg} / \mathrm{kg} \\
\pm 1 \%\end{array}$ & $\begin{array}{c}\text { Fully } \\
\text { independent }\end{array}$ \\
\hline Radioassay & $\begin{array}{c}\text { Determined by } \\
\text { experiment }\end{array}$ & On-line spectrometry & \\
\hline Data access & \multicolumn{2}{|c|}{ Remote real-time visibility } & \\
\hline Safety and environment & \multicolumn{2}{|c|}{$\begin{array}{c}\text { Limit hazardous-mixed waste generation } \\
\text { Two levels of confinement at reactor primary } \\
\text { coolant boundary } \\
\text { Automatic safe shutdown } \\
\text { Shielded container for irradiated experiments } \\
<200 \mathrm{mR} / \mathrm{hr}\end{array}$} & \\
\hline Design Lifetime (years) & 30 & Life of Program & $\begin{array}{l}\text { Component } \\
\text { replacement } \\
\text { acceptable }\end{array}$ \\
\hline
\end{tabular}

\subsection{Facilities Assessment Report}

An important task in the GTL conceptual design was to determine the best facility to serve as host for this apparatus, which would allow fast-flux neutron testing in an existing nuclear facility. A survey was undertaken of domestic and foreign nuclear reactors and accelerator facilities to arrive at that determination. Two major research reactors in the U.S. were considered in detail, the Advanced Test Reactor (ATR) and the High Flux Isotope Reactor (HFIR), each with sufficient power to attain the required neutron fluxes. HFIR routinely operates near its design power limit of $100 \mathrm{MW}$. ATR has traditionally operated at less than half its design power limit of $250 \mathrm{MW}$. Both of these reactors should be available for at least the next 30 years. The other major U.S. research reactor, the Missouri University Research Reactor, does not have sufficient power to reach the required neutron flux nor do the smaller research reactors. Of the 
foreign reactors investigated, BOR-60 was the most attractive. Monju and BN-600 are power reactors for their respective electrical grids. Although the Joyo reactor is vigorously campaigning for customers, local laws regarding transport of radioactive material mean it would be very difficult to retrieve test articles from either Japanese reactor for post irradiation examination. PHENIX was scheduled to close in 2008 and was fully booked until then. India's Fast Breeder Test Reactor is limited to domestic (Indian) users only. Data quality is often suspect in Russia. The only accelerator seriously considered was the Materials Test Station (MTS) proposed for operation at Los Alamos National Laboratory. The neutron spectrum in MTS is similar to that found in a fast reactor except it has a pronounced high-energy tail that is atypical of fast fission reactor spectra. First irradiation in the MTS is being was contemplated for midway through 2010. Detailed review of these facilities resulted in the recommendation that the ATR would be the best host for the GTL. Table 2 lists major comparison findings for Required GTL technical and functional requirements, and Table 3 makes a similar comparison against Desired technical and functional requirements.

\subsection{Conceptual Design}

The Gas Test Loop (GTL) Project Conceptual Design was initiated to determine basic feasibility of designing, constructing, and installing in a host irradiation facility, an experimental vehicle that could replicate with reasonable fidelity the fast-flux test environment needed for fuels and materials irradiation testing for advanced reactor concepts. Initial conceptual design activities were carried out in which more than 30 different configurations, some with booster fuel and some without, were evaluated to a greater or lesser extent. Designs focused on use of one of the ATR corner lobes (NW or NE) where there is a large space available. A significant conclusion from the conceptual design was that the desired fast flux could not be reached without operating the lobe in which the apparatus was located at the relatively high power of about $45 \mathrm{MW}$ and making use of booster fuel, contributing another $6 \mathrm{MW}$ or so. Hafnium filters surrounding the test specimen locations could remove the thermal neutrons reasonably well, providing a fast to thermal ratio greater than 15 .

\subsection{Configuration}

The configuration determined in the initial conceptual design activity to have the greatest potential for success [6] is shown in Figures 1 to 3. 


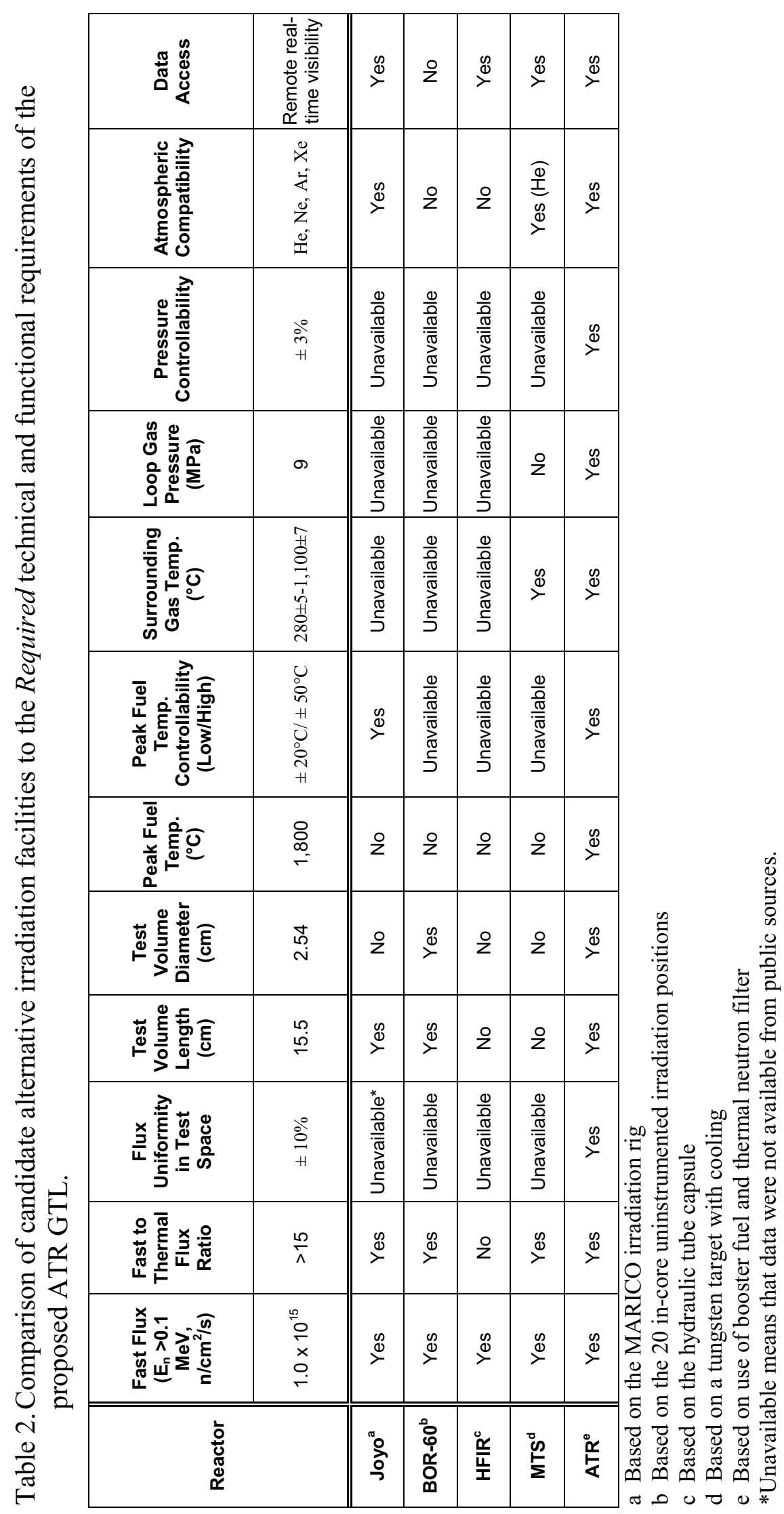




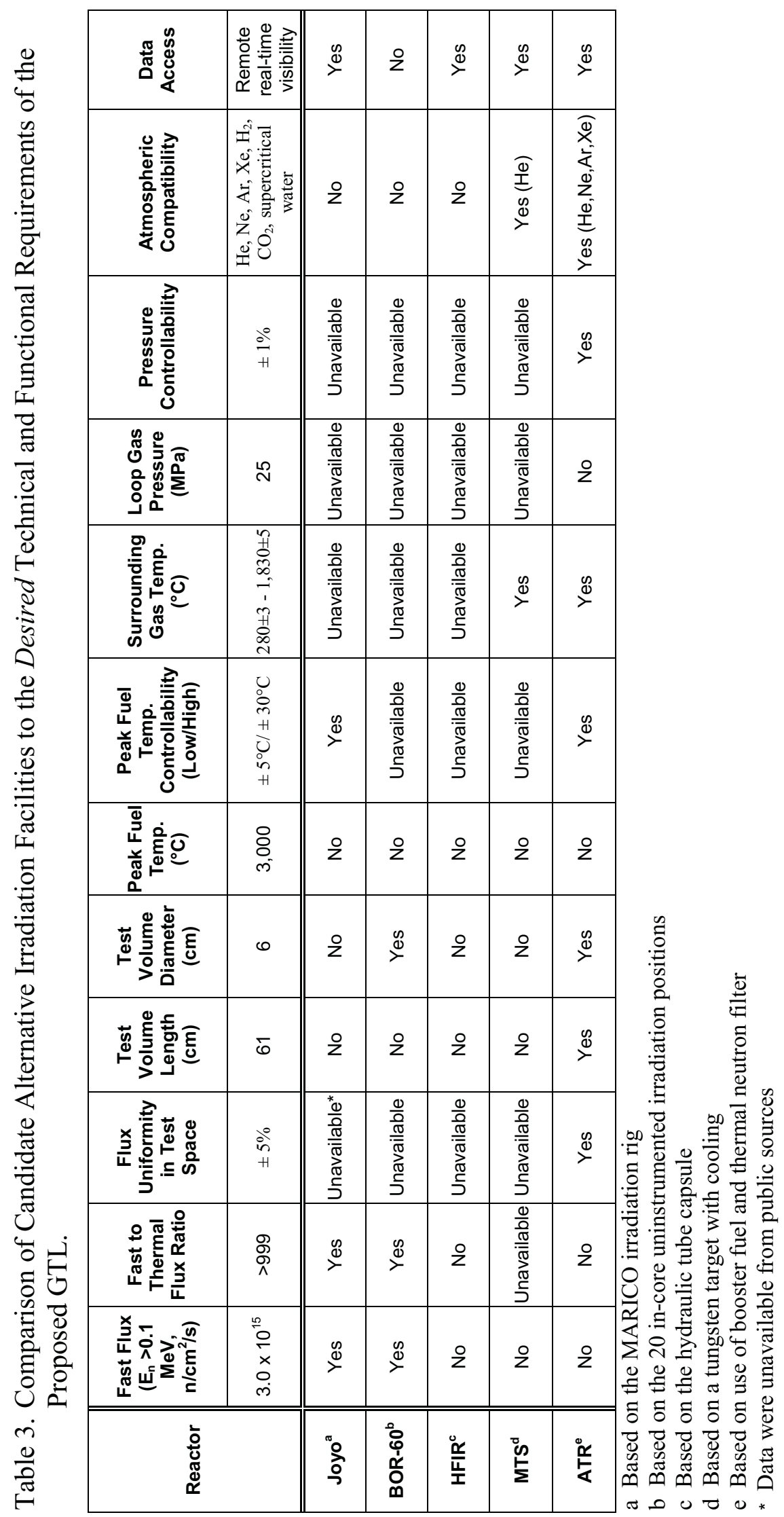




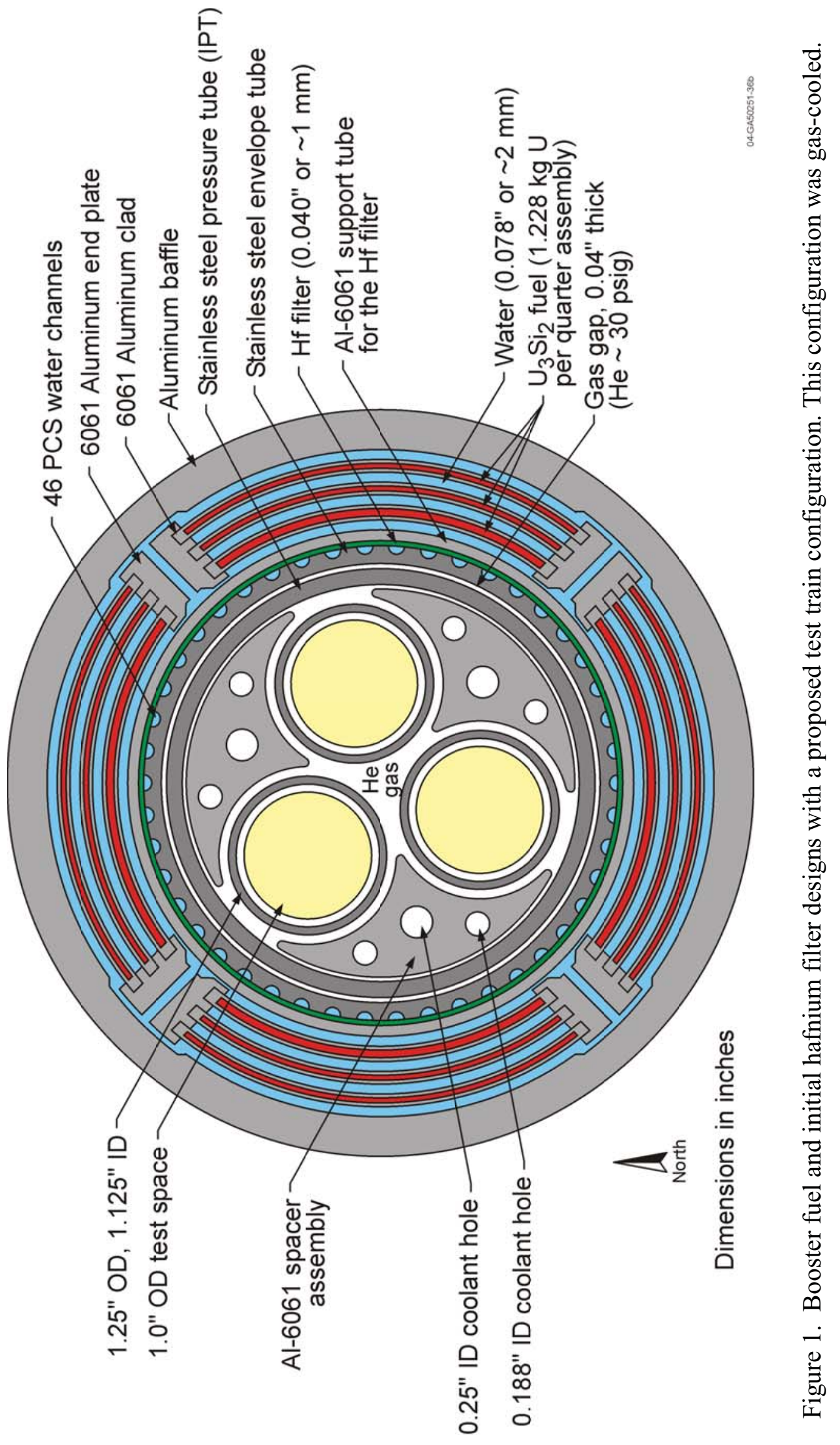




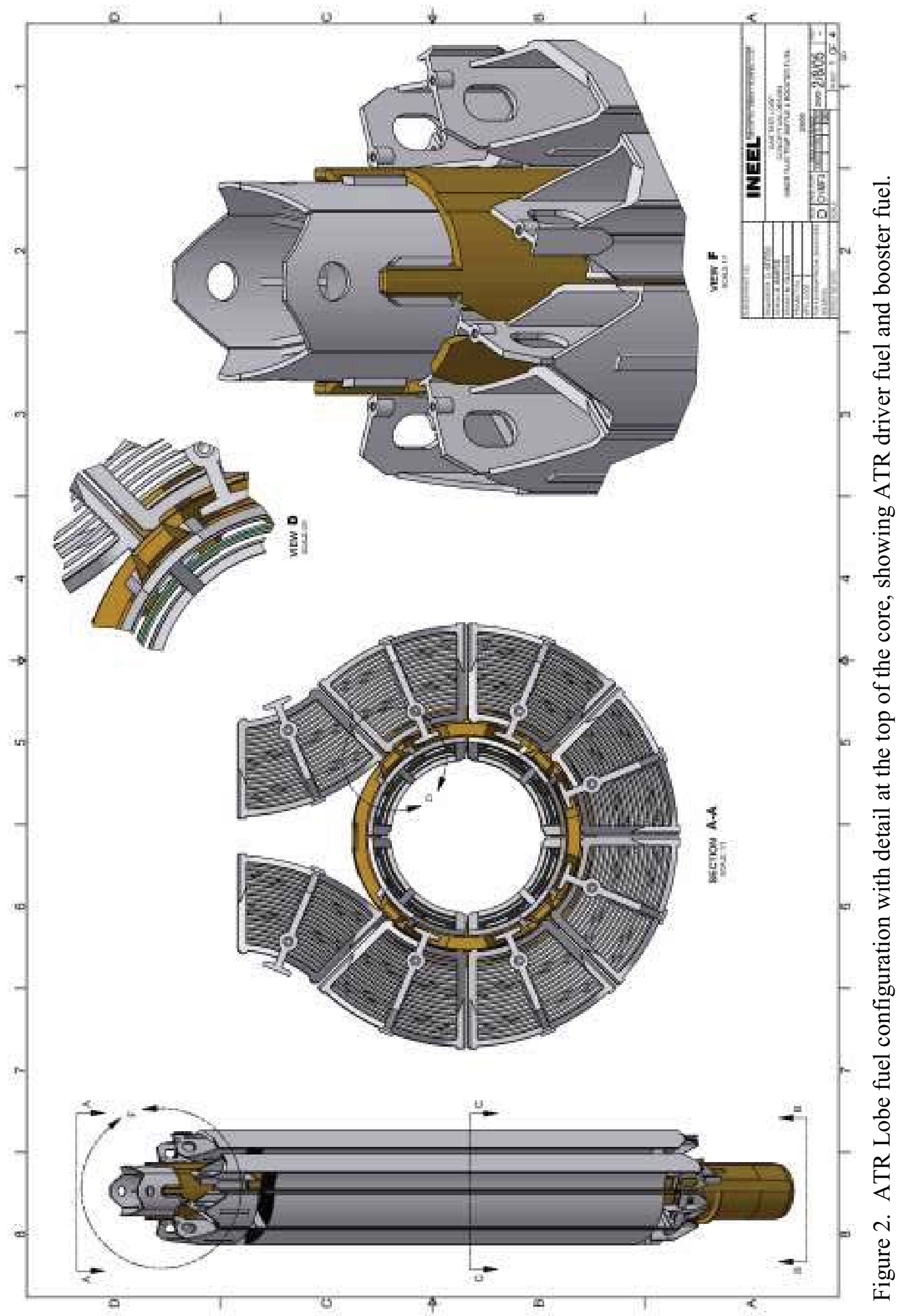




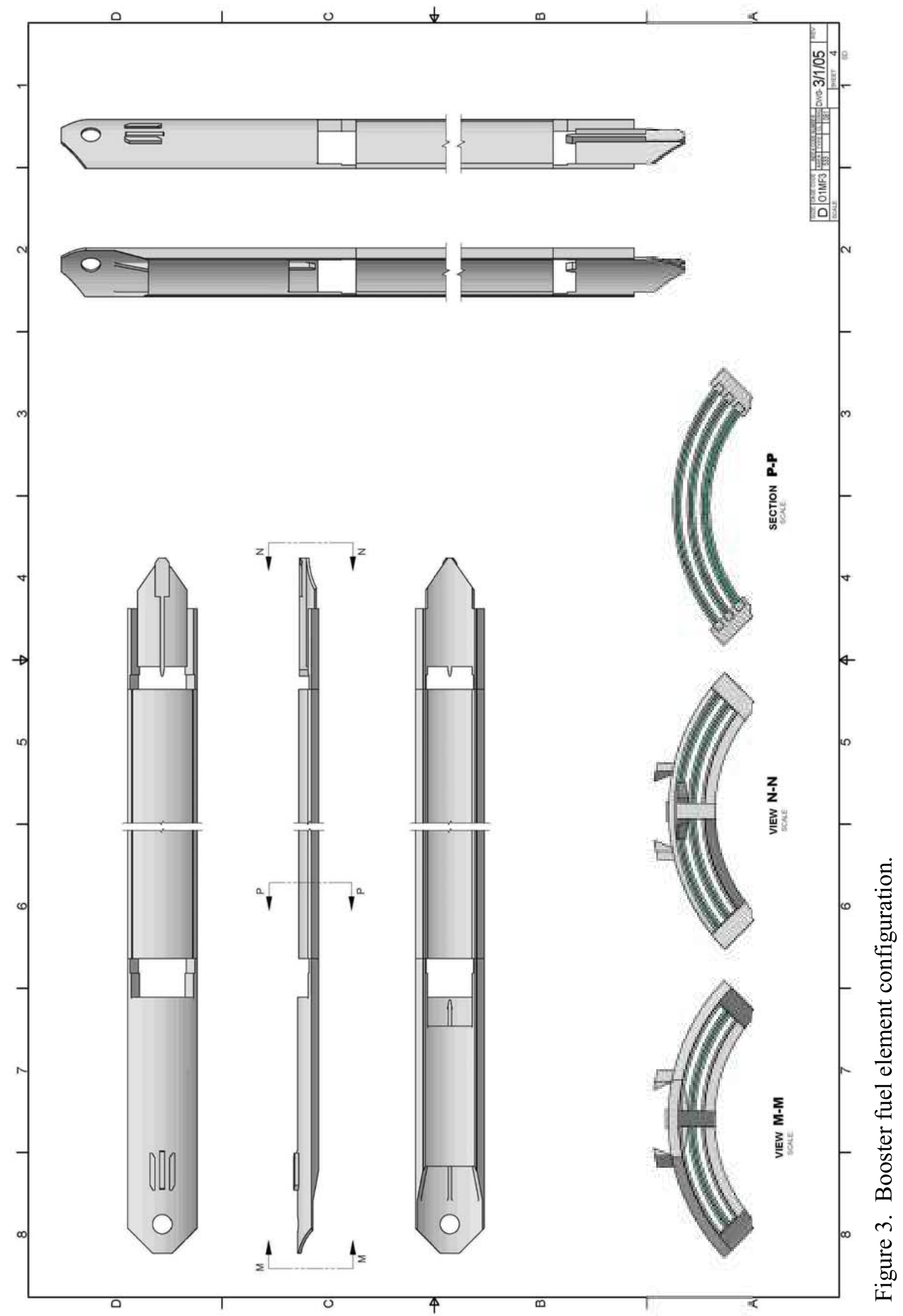


Figure 4 shows how the GTL assembly would fit into the ATR reactor vessel.

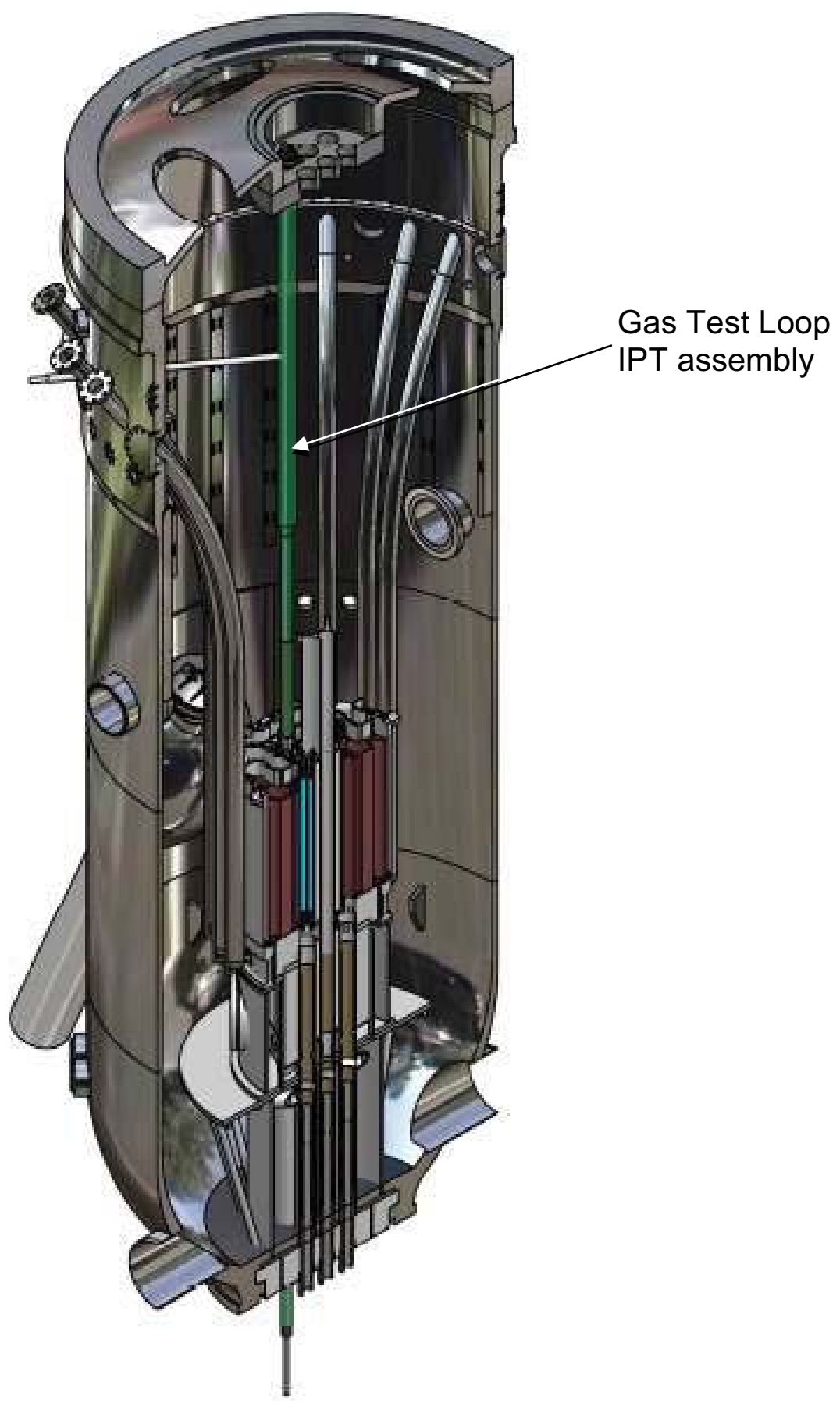

Figure 4. Positioning of the GTL assembly in the ATR reactor vessel.

\subsection{Neutron Filter}

The Technical and Functional Requirements for the GTL stipulated a minimum fast to thermal neutron ratio $>15$ for the test environment. Creating a fast neutron environment (fast to thermal ratio $>15$ ) in a thermal reactor requires the use of a thermal neutron filter or absorber. 
The thermal neutron filter was developed to allow potentially variable flux tailoring at 5 different axial positions. Five axial positions were chosen for this conceptual design; however more or fewer could be used by varying the length of the filter material over the $121-\mathrm{cm}$ (48-inch) core region.

The filter design needed to provide the desired neutron environment, be accessible for removal, replacement, and reconfiguration, and have a reasonable lifetime in the reactor. The other requirements for the filter, besides the absorption of thermal neutrons, included good corrosion properties, long life, and easy accessibility. Hafnium was chosen as the filter material because the properties of hafnium allow it to be placed directly in the primary coolant, and hafnium has significant cross sections in all 6 of its stable isotopes meaning that the effective burn-up rate of hafnium is significantly slower than either boron or cadmium, other materials considered.

The first design (Figure 1) placed the filter on the outside of the pressure tube, making it possible to change the filter without removing any of the test capsules or disassembling the pressure tube. As the design matured, the location of the absorber layer was moved to just outside the test specimen capsules, as shown in Figure 5.

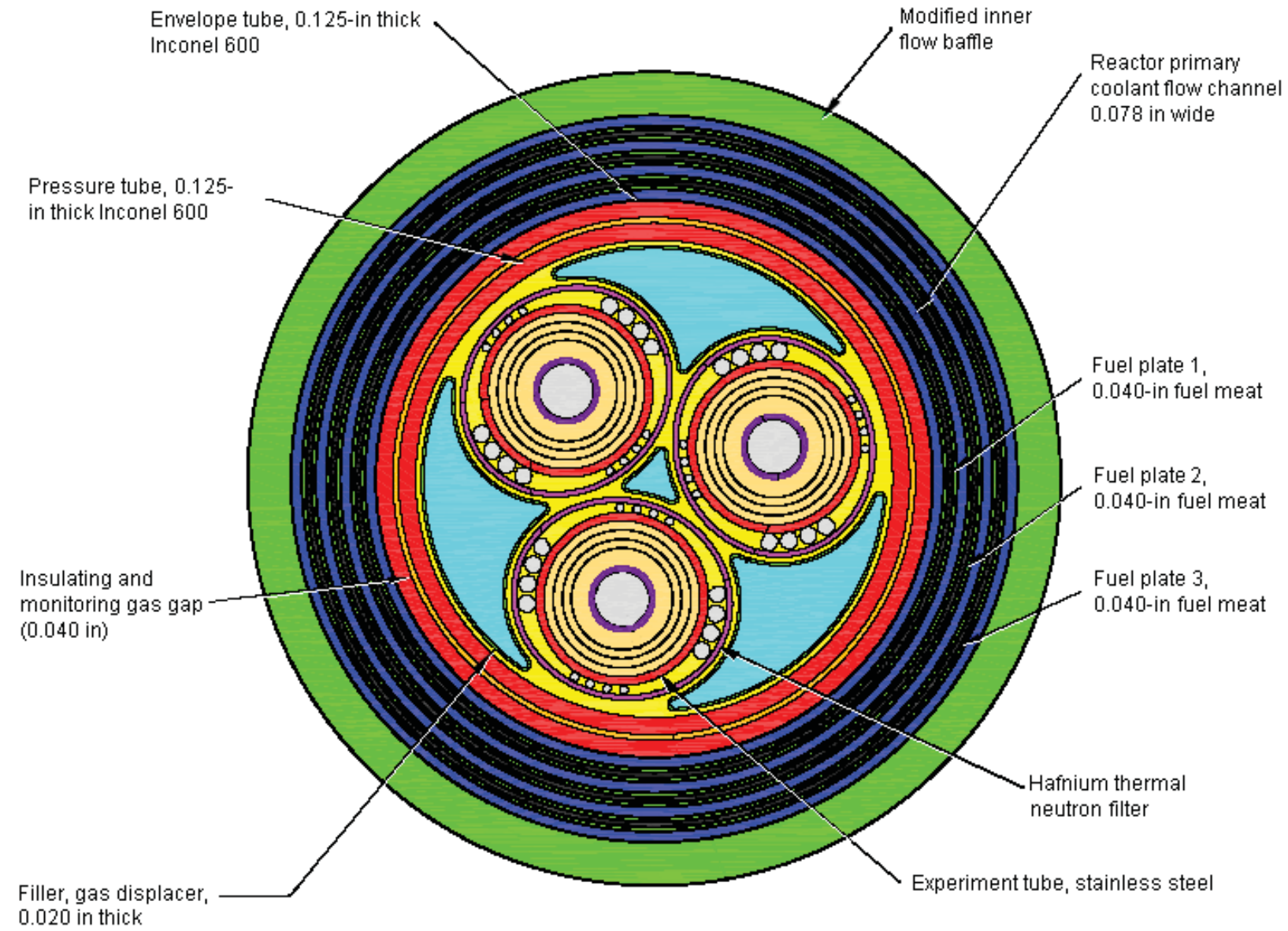

Figure 5. Second design iteration on arrangement of components in the GTL. 
The corrosion properties of hafnium and its slow burn-up rate along with is current use in the reactor made it an obvious choice for the filter. The thickness of the filter was determined using the computer code MCNP version 4C [13]. MCNP was used in conjunction with ORIGEN2 [11] to approximate the filter's lifetime.

The maximum time hafnium could be used in the reactor was based on the total fast neutron fluence of the hafnium. The limit of $5 \times 10^{22} \mathrm{n} / \mathrm{cm}^{2}$ is specified in the Updated Final Safety Analysis Report for the ATR [12]. This limit corresponds to about 1200 full power days based on the MCNP calculations.

It was determined that a 1-mm thick hafnium annulus was enough to provide a fast to thermal ratio of approximately 35 for the specific gas loop assembly used. After 1200 full power days, the fast to thermal ratio only would decrease to $\sim 25$.

In 2007, while looking for ways to cut system costs, it was realized that a major cost driver for the GTL concept was in the pressurized helium cooling system. Approximately $30 \%$ of the total system cost was associated with the gas systems. It was supposed that if a way could be found to remove the heat from the experiment chamber that did not involve the pressurized gas system, the overall project cost could be reduced substantially, and the concept would be more attractive to potential users

There are only two ways to get the heat out of the test specimens and the hafnium filter: convection and conduction. Radiant heat transfer can also be non-trivial at high target temperatures. Convection requires a fluid. Molten metal, molten salt, gases other than $\mathrm{He}$, organics, and water were considered. It was supposed that the cost of molten metal or molten salt systems would be comparable to or greater than that of pressurized gas systems. Furthermore, there were safety concerns about putting into the reactor any fluid that could react with the primary coolant, and it did not appear practical to make use of a fluid that must be kept hot to prevent structural damage. The most viable liquid for use in ATR seemed to be water, where a major concern is fast neutron thermalization.

With the above points in mind, a novel approach was suggested that involves both conduction and water convection. Using this approach, hafnium powder or Hf-Al eutectic powder dispersed in aluminum is cast or extruded into a solid form. This material would retain the high thermal conductivity of aluminum but have the thermal neutron absorption properties of hafnium. With this approach, heat would be removed by conduction from the experiment capsules and carried to a point far enough from the experiment zone to avoid the thermalization of neutrons. There the heat would be conveyed to primary coolant water, which would provide the ultimate sink.

After several configuration iterations and analyses, the implementation of this concept shown graphically in Figure 6 was selected as the most favorable. Calculations were performed to assess the effect of hafnium concentration on the fast-to-thermal flux ratio using the MCNP code [13] with a numerical model approximating the configuration of Figure 6 . The results are shown in Figure 7. 


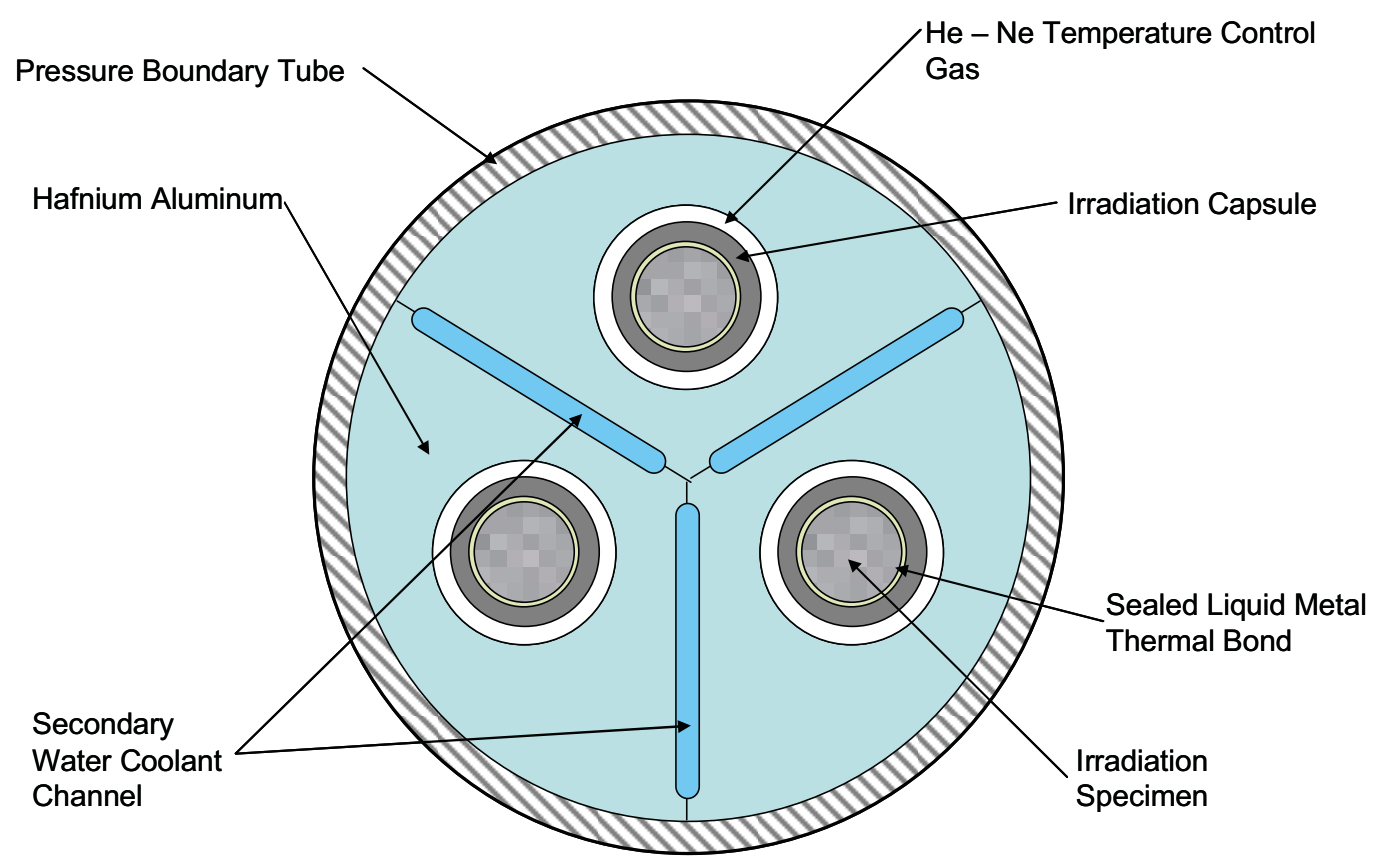

Figure 6. Dispersed thermal neutron absorber concept.

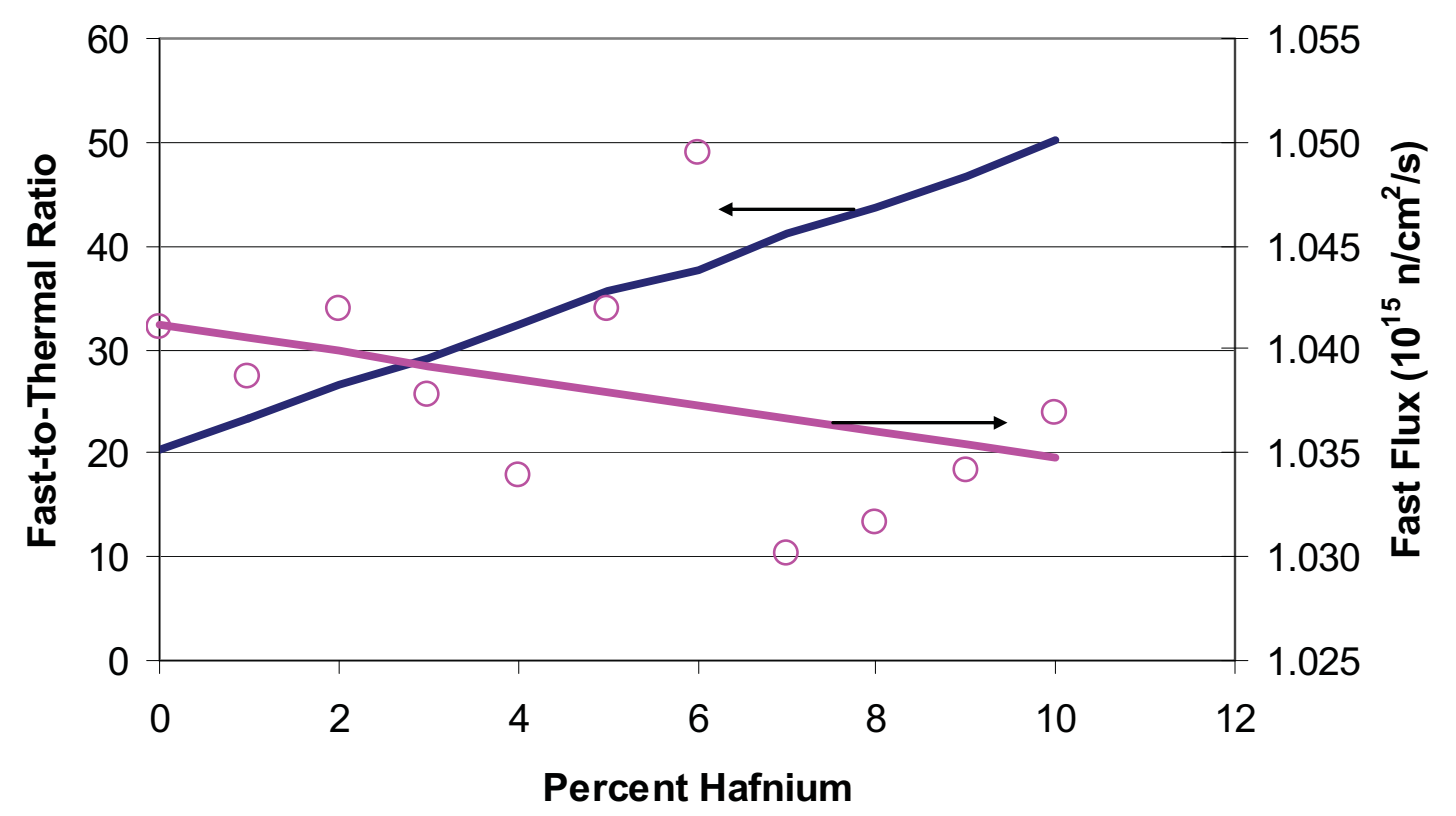

Figure 7. Fast-to-thermal ratios and fast flux attainable with the dispersed thermal neutron absorber.

Other thermal neutron absorber materials, such as cadmium, were also considered. While these produce a slightly greater fast-to-thermal flux ratio, the relatively shorter effective life of those 
materials means more frequent thermal neutron absorber changes relative to hafnium. Once a hafnium neutron filter assembly is no longer useful it may be disposed of as ordinary radioactive waste, subject to applicable waste acceptance criteria for the disposal site. Most of the hafnium activation products from neutron absorption are relatively short lived or very long-lived. Exceptions are Hf-178, which emits 426.4 and $325.6 \mathrm{keV}$ gamma rays with a 31 year half-life. Hf-182 has a 270.4-keV gamma with a 9 million year half-life, and $\mathrm{Hf}-174$ emits a $2.5-\mathrm{MeV} \alpha$ particle but its half-life is $2 \times 10^{15}$ years [14].

More details regarding this approach and prospects for the Hf-Al performance are in Ref. [8]. Key performance issues identified there include changes in the thermal conductivity and chemical stability, including corrosion by the ATR primary coolant, of the Hf-Al compound associated with transmutations due to neutron irradiation. A proposal from Utah State University to investigate those issues was presented to and accepted by the ATR National Scientific User Facility program. The project includes developing manufacturing methods for the material, evaluating its thermal and chemical properties outside of the reactor, and finally performing irradiation experiments on samples of the material and performing PIE to evaluate changes in those properties. Most of that work will be conducted in FY-2009 and FY-2010.

\subsection{Booster Fuel Design}

As illustrated in Figures 1 to 3, the booster fuel occupies an annulus between a modified flux trap baffle (a tube to which the ATR fuel elements are attached) and the test loop containment.

The conceptual design for the booster fuel elements comprises four booster fuel plate assemblies each containing 3 curved fuel plates. The fuel meat in the booster fuel is aluminum-dispersed uranium silicide $\left(\mathrm{U}_{3} \mathrm{Si}_{2}\right)$ whereas ATR fuel is $\mathrm{UAl}_{\mathrm{x}}, \mathrm{x} \sim 3$. Uranium silicide fuel offers significantly higher uranium density than the $\mathrm{U}-\mathrm{Al}_{\mathrm{x}}$ fuels currently used as driver fuel in the ATR and has demonstrated outstanding in-reactor performance. Cladding for both booster fuel and ATR fuel plates is aluminum (alloy 6061). While these plates resemble plates from the ATR fuel elements, they are different in several ways. Fuel loading densities in the booster fuel meat are higher at $4.8 \mathrm{gU} / \mathrm{cm}^{3}$. The cladding thickness of all three plates is similar to that of plate 19 on the ATR driver fuel. The booster fuel plates are swaged into aluminum side plates in a manner similar to the ATR driver fuel elements. The thickness of the coolant channels is similar to that of the ATR driver fuel. Top and bottom end boxes of cast aluminum are welded to the booster fuel side plates. The clearances associated with the booster fuel elements are similar to those of the driver fuel elements. Each booster fuel element encompasses approximately 90 degrees of arc, rather than the 45 degrees of the ATR driver fuel, so that 4 elements surround the experiment pressure boundary.

A fairly circumspect process was used to select and optimize the booster fuel design from the neutronics and thermal hydraulics perspectives. More than 20 different concepts were explored. Three were chosen for more detailed analysis, and they were narrowed to the configuration shown in Figures 1 through 3.

Analyses showed that the best performance will be achieved when the booster fuel meat thickness is 0.040 inch $(1.02 \mathrm{~mm})$ in the outer two plates and 0.060 inch $(1.52 \mathrm{~mm})$ in the inner plate. Peak surface heat fluxes on the booster fuel are expected to reach $550 \mathrm{~W} / \mathrm{cm}^{2}$. 


\subsection{Gas System Design}

The gas systems of the Gas Test Loop were not designed in the same detail as other elements of the GTL. They were developed sufficiently to form a basis for high-level cost estimates. It was considered that the detailed gas systems design would be more or less routine once the physics issues associated with the fast neutron production were resolved. Later in the program, when the change was made to the dispersed neutron absorber, there was a major modification to the general configuration of the gas systems.

The initial configuration of gas cooling system consisted of two independent parts: a "Gas Coolant Loop" used for removing heat from the experiment, and a "Specimen Environment Control and Sample Carrier System" for temperature control (gas-gap conductance) and fission product sampling in the control gas (see Figure 8).

\subsubsection{Gas Coolant Loop}

The primary function of the Gas Coolant Loop was to provide a heat sink for heat generated within the experiment space. Helium was chosen as the gas coolant medium due to its being inert, single phase, with no reactivity effects. It was estimated that the Gas Coolant Loop would be required to remove approximately $200 \mathrm{~kW}$ from the experiment area. Scoping calculations indicated the loop would have to be operated at a mass flow rate near $2270 \mathrm{~kg} / \mathrm{hr}(5000 \mathrm{lb} / \mathrm{hr})$ at $1.72 \mathrm{MPa}(250 \mathrm{psi})$ to achieve the bulk exit gas temperature of less than $422 \mathrm{~K}\left(300^{\circ} \mathrm{F}\right)$. It was also estimated that at operating pressure the entire gas coolant loop would contain around $2.5 \mathrm{~kg}$ of helium, which could be supplied by less than three standard size 15.2-MPa (2200-psi) helium bottles.

\subsubsection{Specimen Environment Control and Sample Carrier System}

The primary function of the Specimen Environment Control and Sample Carrier System was to provide a means of controlling the temperature and environment surrounding the experiment. Each test capsule could be supplied with an independent flowing gas blend (helium/neon is typical of past experiments) to control the test temperature. If a test sponsor had a special test environment need, alternate gases could be introduced into the test capsule through this system. The experiment could be designed such that heat generated in the experiment would be transferred by conduction through the gas blend gap to the test capsule wall. The heat would then be conducted through the test capsule wall to the heat sink provided by the Gas Coolant Loop. Adjusting the blend of the two control gases, which have different thermal conductivity properties, would aid in controlling the temperature of the test specimens.

A secondary function of this system was to provide a carrier gas to transport gases emitted from experiments to a sample system. The sample system was to be dependent upon experimenters needs. These systems would include various forms of gas chromatography and spectral analysis.

The Specimen Environment Control and Sample Carrier System consisted of 15 independent gas channels capable of controlling the temperature of and obtaining gas samples from 15 different 


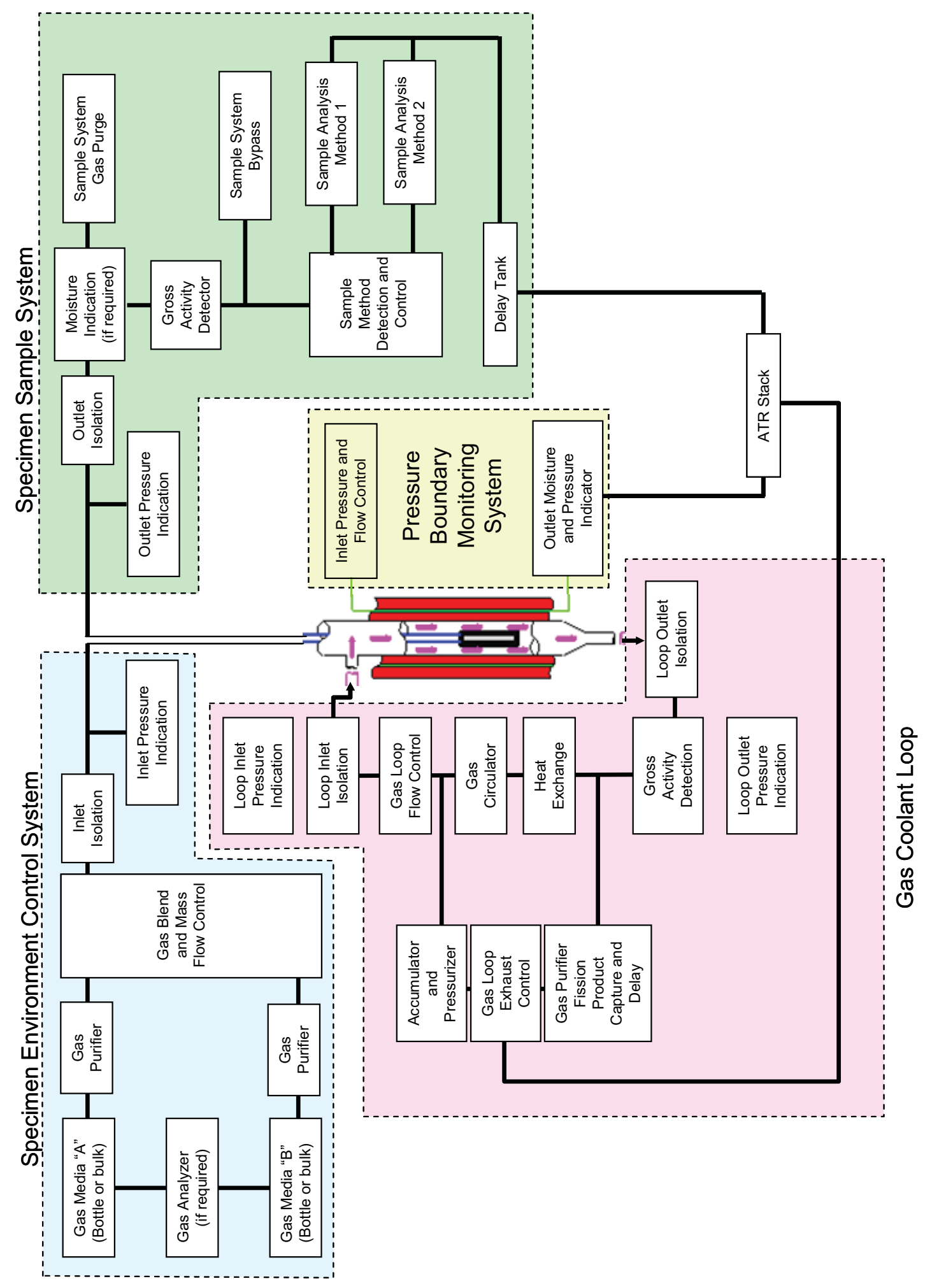


experiment test capsules. The design could support up to 3 different test trains, with up to 5 independent test capsules in each test train. It was estimated that the flow rate for the Specimen Environment Control and Sample Carrier System would be around 60 standard cubic centimeters per minute ( $\mathrm{sccm}$ ) at system inlet pressure of less than $34 \mathrm{kPa}$ (50 psi). The system was designed as a single pass system; the gas blend exiting the experiment capsule would be delayed, as appropriate for fission product decay, and then released to the ATR stack.

\subsection{Hydraulic Testing}

Because the design pushed established safety limits for thermal-hydraulic performance, it was important to establish actual coolant flow velocities and pressure loss coefficients for the booster fuel. This was accomplished by tests on a high-fidelity non-nuclear model in the Thermal Fluids Laboratory of Idaho State University [15 A circulation loop was designed and constructed by the university to provide reactor-relevant water flow rates to the test system. The flow channel was a replica of an ATR flux baffle assembly with representative upper and lower flow plena, which was designed and fabricated by the INL. Models of the four booster fuel elements required for GTL operation were fabricated from aluminum (no uranium or means of heating) and placed in the flow channel. One of these was instrumented with Pitot tubes to measure flow velocities in the channels between the three booster fuel plates and between the innermost and outermost plates and the side walls of the flow annulus. Flow coefficients in the range of 4 to 6.5 were determined from the measurements made for the upper and middle parts of the booster fuel elements. The flow coefficient for the lower end of the booster fuel and the sub-core flow channel was lower at 2.3. Figures 9 to 13 show various aspects of the hydraulic test program.

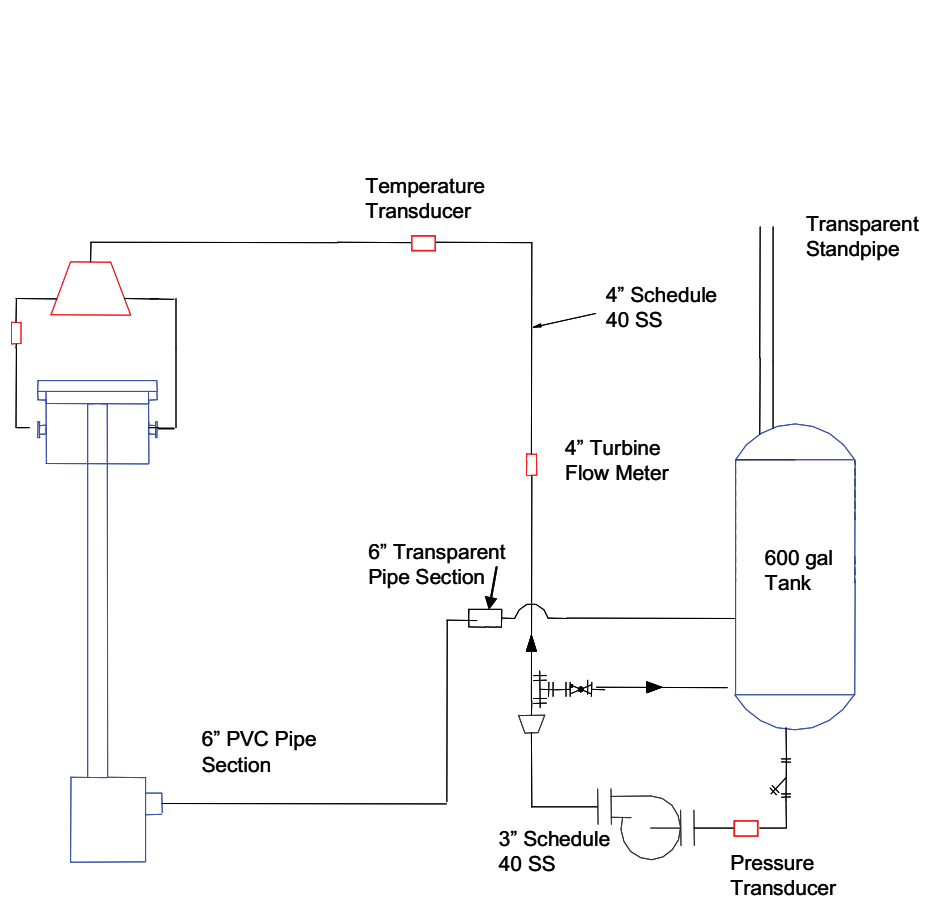

(a)

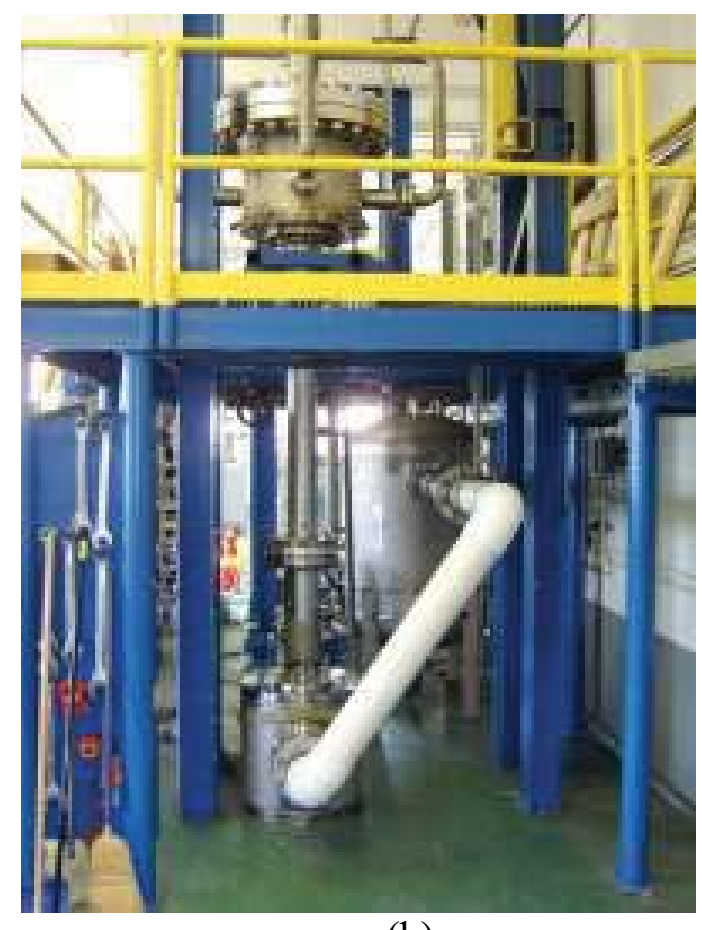

(b)

Figure 9. Schematic (a) and implementation (b) of the hydraulic test loop used for measuring the flow coefficient of the proposed BFFL booster fuel. 


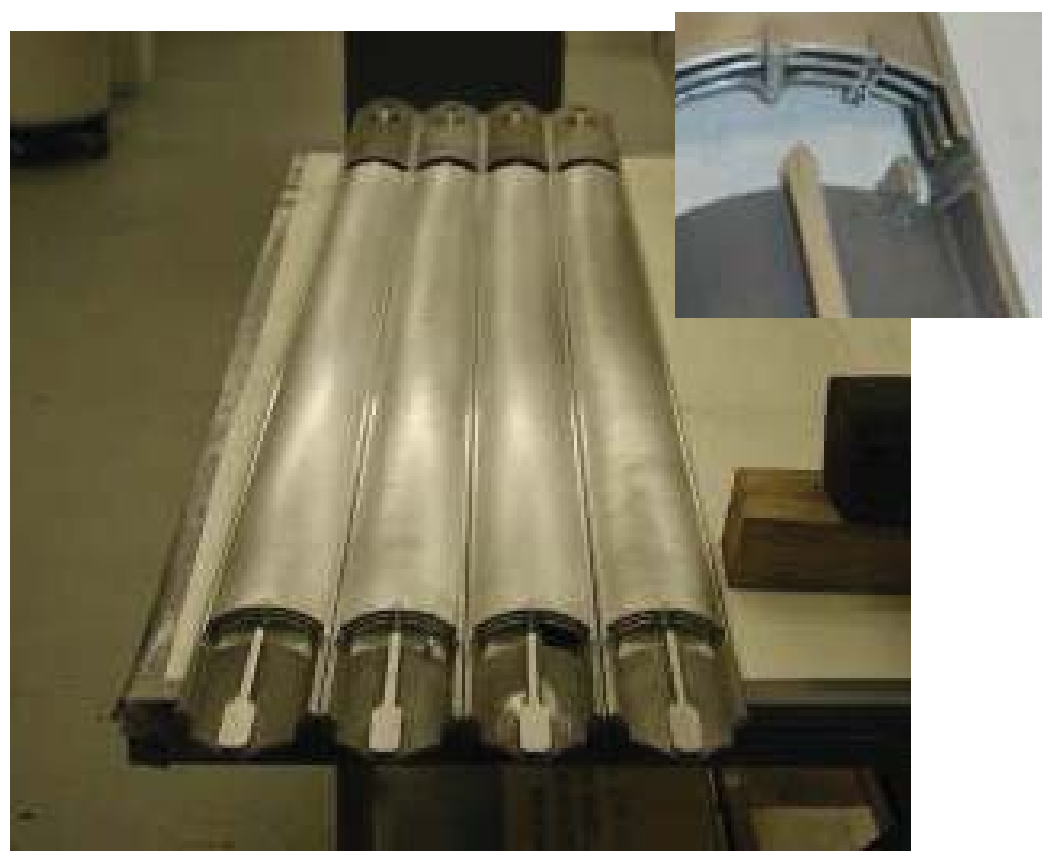

Figure 10. Model booster fuel assemblies. The second from the left has brackets (inset) to hold the Pitot tubes used to measure flow velocities.

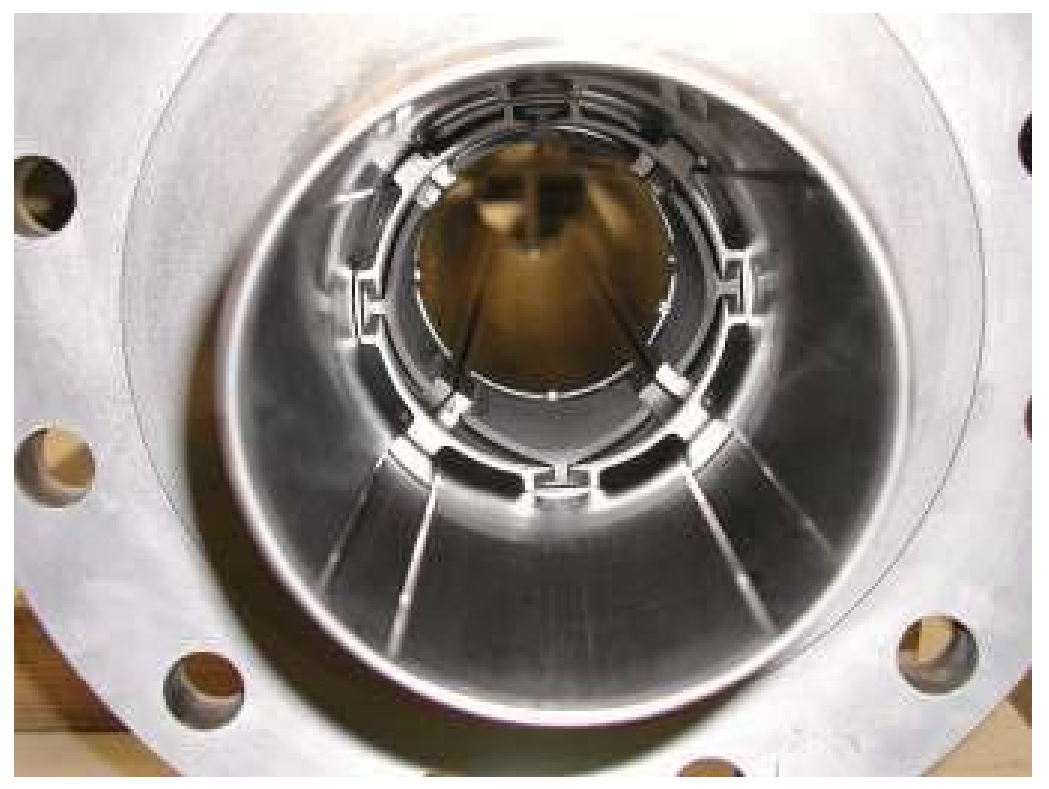

Figure 11. View of the lower support ring in the model flow baffle assembly from below with the model booster fuel elements installed. 


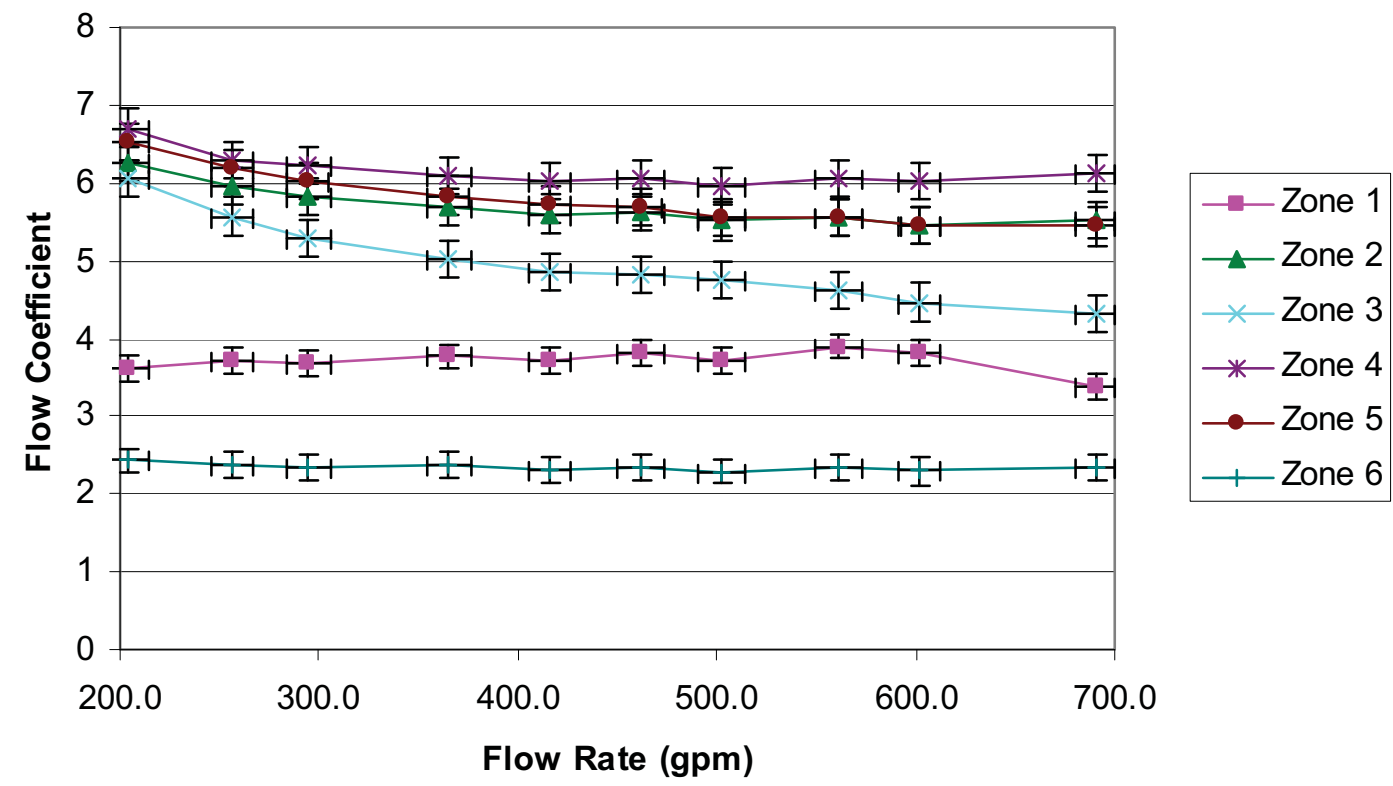

Figure 12. Flow coefficients derived from flow and pressure-drop data for the model booster fuel elements. Zones are (1) upper end cap, (2) inside innermost fuel plate, (3) between innermost fuel plate and middle fuel plate, (3) between middle fuel plate and outermost fuel plate, (4) outside outermost fuel plate, (5) lower end cap, and (6) flow distribution tank 


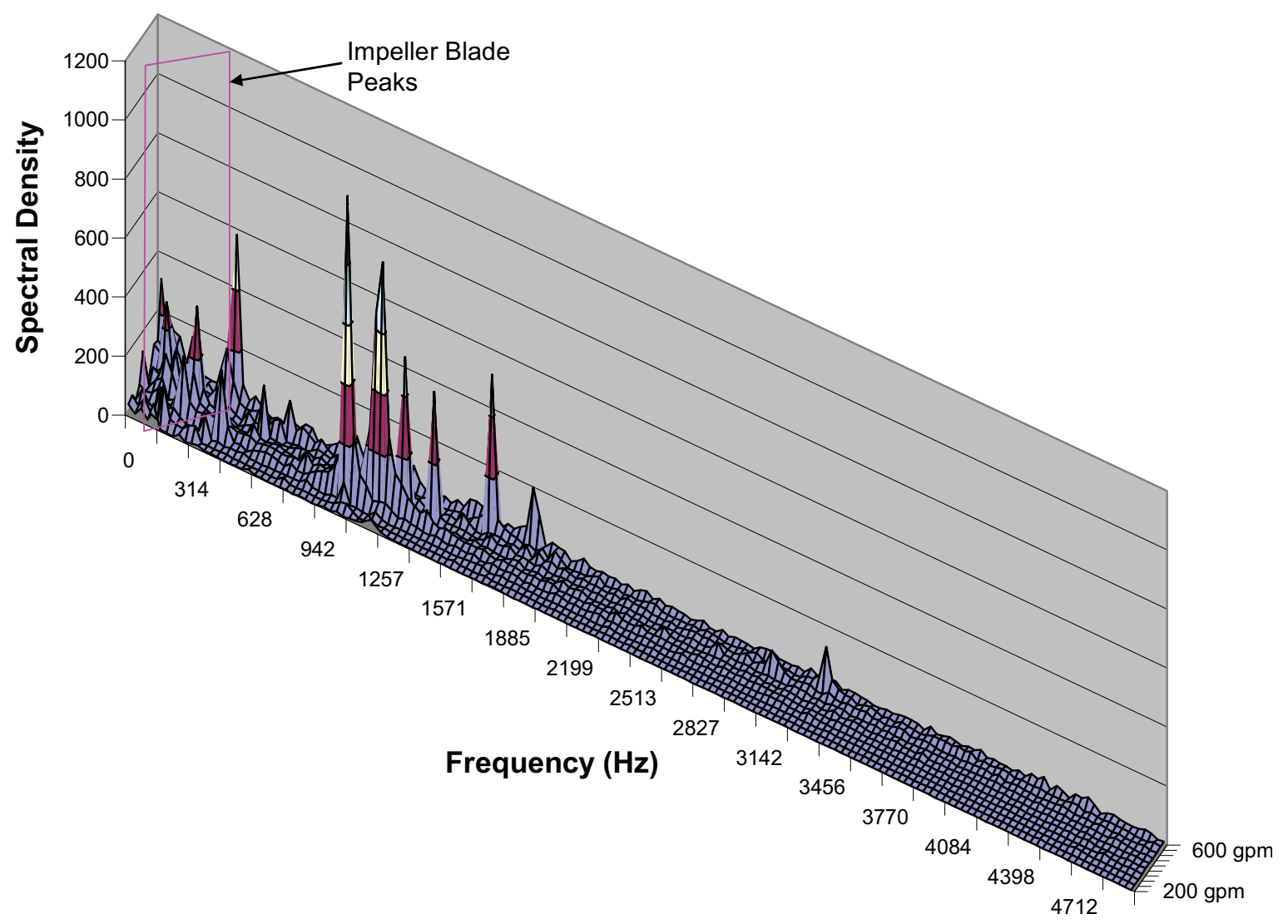

Figure 13. Composite plot of spectral density for the dynamic pressures recorded. Peaks in the 900 - to $1400-\mathrm{Hz}$ range were believed generated by vortex shedding over fuel plate leading edges.

The dynamic pressure sensor, located at the vertical mid-point of the model booster fuel, recorded high-speed data for the purpose of identifying drivers for flow-induced vibrations in the model booster fuel element. Discrete Fourier transform analysis was performed on those data to obtain the frequency spectral density of the pressure oscillations (as shown in Figure 13) for each of the 10 flow rates. A prominent range of peaks beginning at about $115 \mathrm{~Hz}(203.8 \mathrm{gpm})$ and increasing to about $360 \mathrm{~Hz}(690 \mathrm{gpm})$ is highlighted by the pink box in the figure. These peaks correspond with the frequency at which the impeller blades passed the pump outlet. Another set of prominent peaks occurs in the 1,000 to $1,800 \mathrm{~Hz}$ range. At the lower flow rates, these peaks are much smaller and minor peaks are present at higher and lower frequencies. These are believed to be due to vortex shedding at the inlet to the model fuel plate channels. The only other persistent pattern detected in the spectral data was a series of peaks in the 60 to $90 \mathrm{~Hz}$ range, which are attributed to electrical noise in the measurement system. The presence of other strong peaks at low frequencies, particularly at intermediate flow rates, is suspected to be due to mechanical vibration associated with the pumping system. This phenomenon is discussed in more detail in Ref. [16]. 


\subsection{Booster Fuel Development}

Although uranium silicide fuel, chosen for the booster fuel plates, had performed well in irradiation experiments, there was uncertainty about two major aspects of its use. One was the ability to fabricate booster fuel elements with their greater meat thickness and smaller radius of curvature than plates made for the ATR. The second was the corrosion potential of its aluminum cladding at the high heat fluxes and fuel swelling at the high temperatures required in this application. The fabrication issue was addressed by a fabrication development program initiated at BWXT Nuclear Products Division of Lynchburg, VA. Irradiation testing in the ATR of small "mini-plates" with prototypic construction and at heat fluxes and coolant flow velocities typical of the booster fuel provided answers to the corrosion and swelling questions.

\subsection{Booster Fuel Fabrication Assessment}

Uranium silicide plates of the required fuel loading, meat thickness and curvature had not been previously made. BWXT, who furnishes ATR reactor fuel, was commissioned to demonstrate their ability to fabricate booster fuel plates for the GTL, first with depleted uranium, and then with HEU in a plate planned for irradiation in the ATR central flux trap to demonstrate successful performance. The fabrication study was initiated but not completed due to funding limitations. The bending of aluminum plates to the shorter bend radius was demonstrated, but no actual fuel plates were produced.

\subsection{Mini-Plate Irradiation Testing}

The initial GTL booster fuel development plan included testing of mini-plates to answer fundamental questions about the performance of the fuel form, notably corrosion, then the testing of a full size fuel plate to demonstrate successful fabrication. That was to be followed by verification testing of complete booster fuel assemblies. Only mini-plate testing was completed.

\subsubsection{Specimen Preparation}

Mini-plates were fabricated and tested using standard methods. Fuel meat pucks were prepared by vacuum arc melting. These were then placed in multi-element aluminum frames, sandwiched between aluminum cladding plates, and rolled to the required thickness (see Figure 14). 


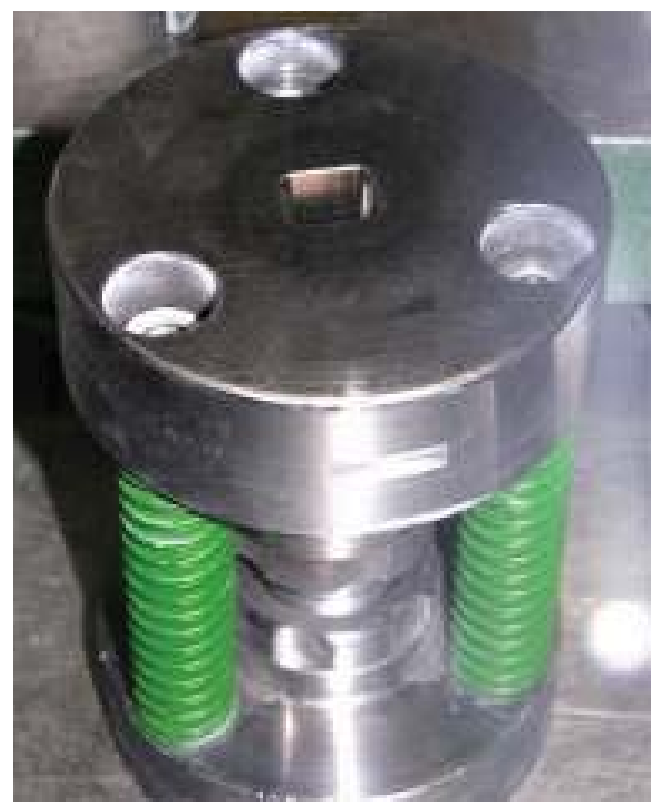

(a)

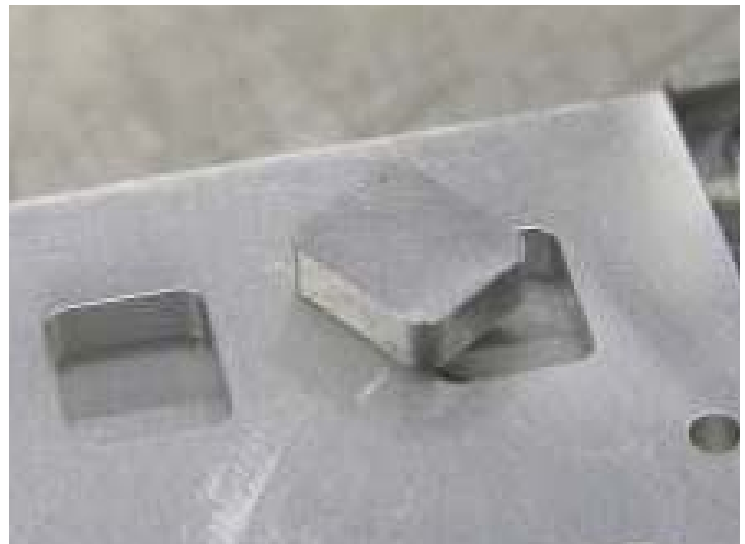

(b)

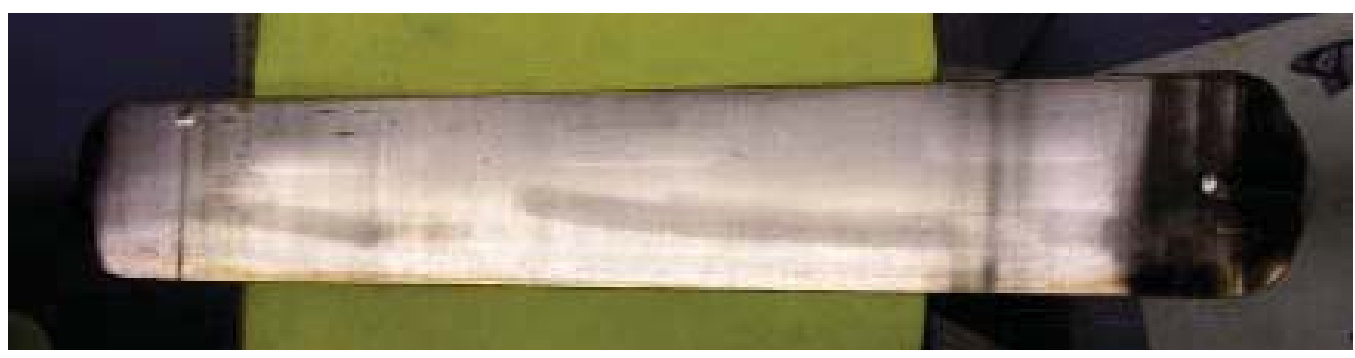

(c)

Figure 14. Elements of mini-plate fabrication: (a) fuel meat compact forming die, (b) Compact placement in frame before welding of cladding plates, and (c) Rolled plate with 6 mini-plates before cutting.

Figure 15 shows the mini-plate dimensions and their cross-sectional arrangement in the irradiation canister.
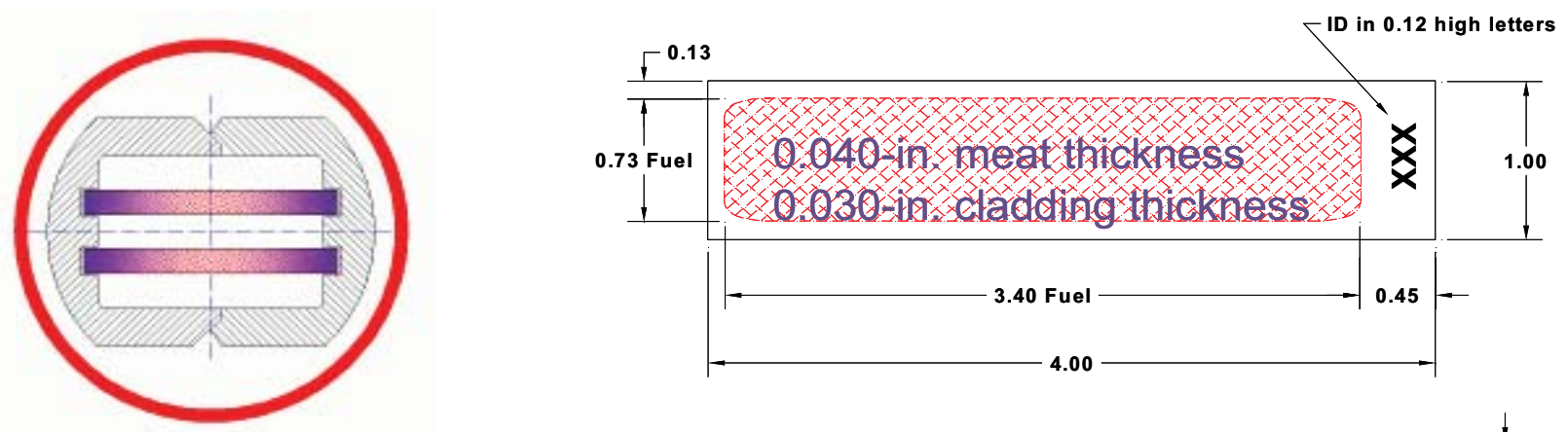

GTL Mini-Plate Test Fuel 
Figure 15. Booster fuel mini-plate dimensions and mounting configuration.

The original GTL mini-plate experiments were planned to be conducted in the ATR B-11 test position. When it was discovered that high Outer Shim Control Cylinder rotation angles would cause power excursions that would render the experiments in Large B positions unsafe and because many of the samples prepared for those tests were found to be of insufficient quality because of a rolling mill failure during fabrication, it was decided to abandon testing in a Large B position and to conduct testing in one of the ATR Flux Traps. The South Flux Trap was available in the time frame needed, so these tests were conducted in the South Flux Trap.

\subsubsection{Irradiation Testing}

Sixteen mini-plates were installed in four capsules, 4 to a capsule. Table 4 lists the basic attributes of the specimens tested and their placement in the capsules. The embedded figure shows the configuration of the capsules within the basket assembly used to position the capsules within the space in the South Flux Trap.

The capsule irradiation was for 48.9 effective full power days in ATR Cycle 143-B. Average reactor lobe power was $25.9 \mathrm{MW}_{\text {th }}$.

\subsubsection{Post-Irradiation Examination}

Following the irradiation, the capsules were removed from the carrier basket and taken to the Hot Fuels Examination Facility for PIE. The first examination was visual inspection. Figure 16 shows front and back images from that visual inspection on one of the specimens, US16DM. These images are typical of all the specimens. The variations in the color along the surface of the plate signify variations in the oxide composition and/or thickness. No defects or problems were seen during the visual examinations. 
Table 4. Matrix of specimen characteristics for GTL mini-plates irradiated in the ATR South Flux Trap.

\begin{tabular}{|c|c|c|}
\hline \multicolumn{3}{|c|}{ GTL-1 Test Matrix } \\
\hline \multirow{4}{*}{ 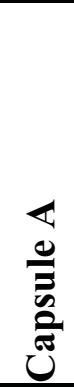 } & $\mathbf{A 1}$ & A2 \\
\hline & $\begin{array}{l}\text { Standard Powder } \\
\text { Standard Pre-film } \\
\text { US06CS }\end{array}$ & $\begin{array}{l}\text { Standard Powder } \\
\text { Modified Pre-film } \\
\text { US15DM }\end{array}$ \\
\hline & $\mathbf{A 3}$ & A4 \\
\hline & $\begin{array}{l}\text { Standard Powder } \\
\text { Standard Pre-film } \\
\text { US03HS }\end{array}$ & $\begin{array}{l}\text { Standard Powder } \\
\text { Standard Pre-film } \\
\text { US11GS }\end{array}$ \\
\hline \multirow{4}{*}{$\frac{\infty}{0}$} & B1 & B2 \\
\hline & $\begin{array}{l}\text { Standard Powder } \\
\text { Standard Pre-film } \\
\text { US04GS }\end{array}$ & $\begin{array}{l}\text { No Fines Powder } \\
\text { Standard Pre-film } \\
\text { UN01ES }\end{array}$ \\
\hline & B3 & B4 \\
\hline & $\begin{array}{l}\text { Standard Powder } \\
\text { Standard Pre-film } \\
\text { US02FS }\end{array}$ & $\begin{array}{l}\text { Annealed Powder } \\
\text { Standard Pre-film } \\
\text { UA01FS }\end{array}$ \\
\hline \multirow{4}{*}{ 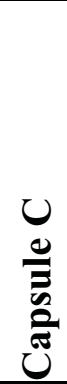 } & $\mathrm{C1}$ & $\mathrm{C2}$ \\
\hline & $\begin{array}{l}\text { Standard Powder } \\
\text { Standard Pre-film } \\
\text { US07FS }\end{array}$ & $\begin{array}{l}\text { Standard Powder } \\
\text { Modified Pre-film } \\
\text { US16DM }\end{array}$ \\
\hline & $\mathbf{C 3}$ & $\mathrm{C} 4$ \\
\hline & $\begin{array}{l}\text { Standard Powder } \\
\text { Standard Pre-film } \\
\text { US08CS }\end{array}$ & $\begin{array}{l}\text { Standard Powder } \\
\text { Standard Pre-film } \\
\text { US14DS }\end{array}$ \\
\hline \multirow{5}{*}{ 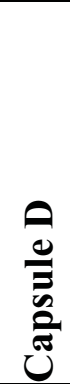 } & D1 & D2 \\
\hline & $\begin{array}{l}\text { Standard Powder } \\
\text { Standard Pre-film } \\
\text { US09FS }\end{array}$ & $\begin{array}{l}\text { No Fines Powder } \\
\text { Standard Pre-film } \\
\text { UN03ES }\end{array}$ \\
\hline & D3 & D4 \\
\hline & Standard Powder & Standard Powder \\
\hline & $\begin{array}{l}\text { Standard Pre-film } \\
\text { US13GS }\end{array}$ & $\begin{array}{l}\text { Modified Pre-film } \\
\text { US17GM }\end{array}$ \\
\hline
\end{tabular}

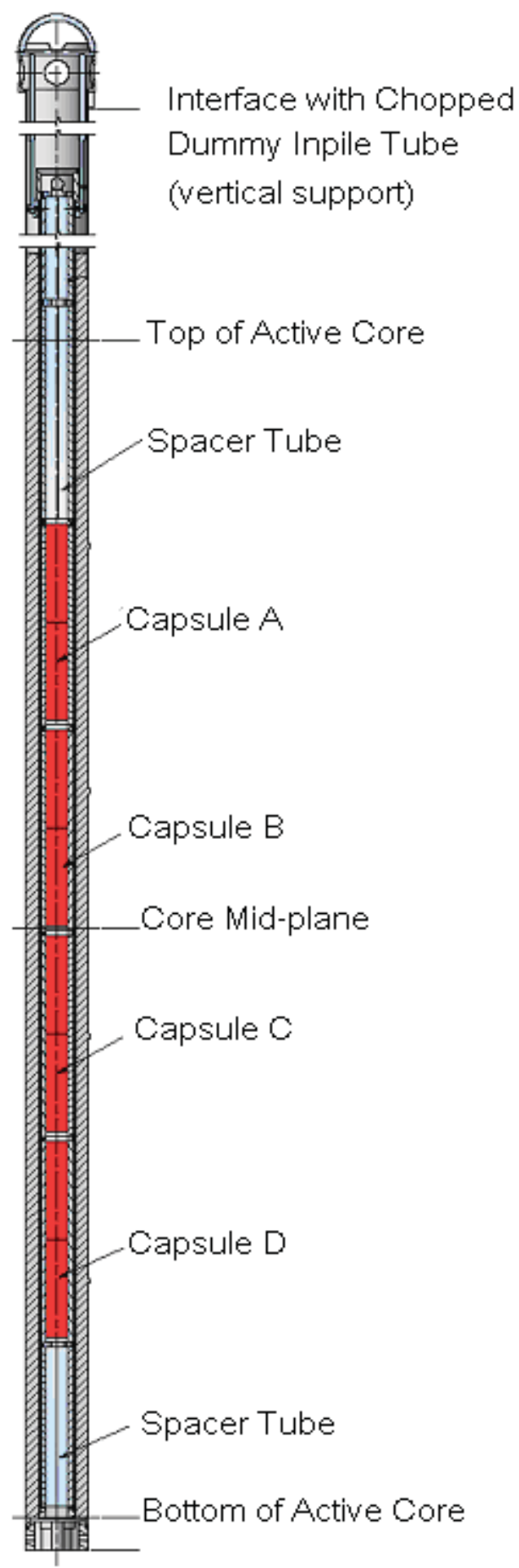




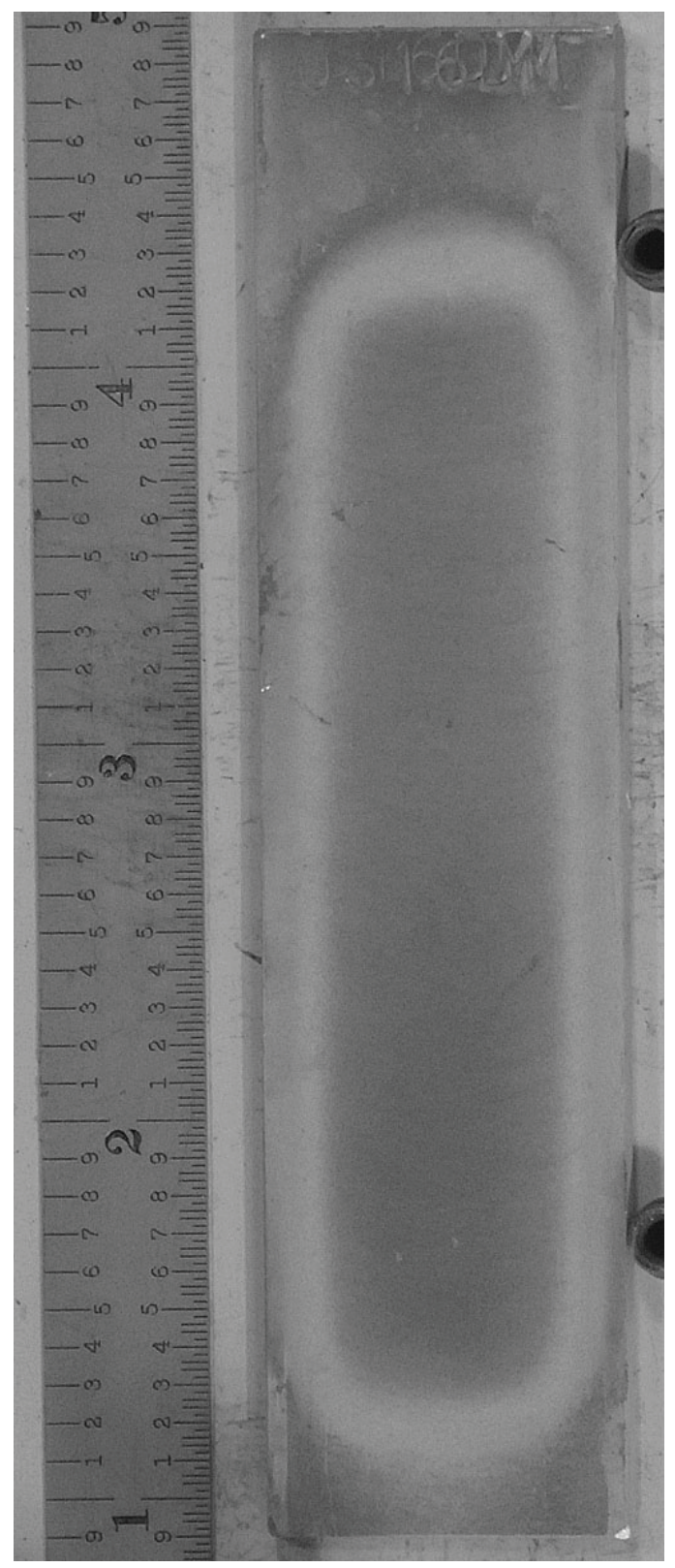

(a)

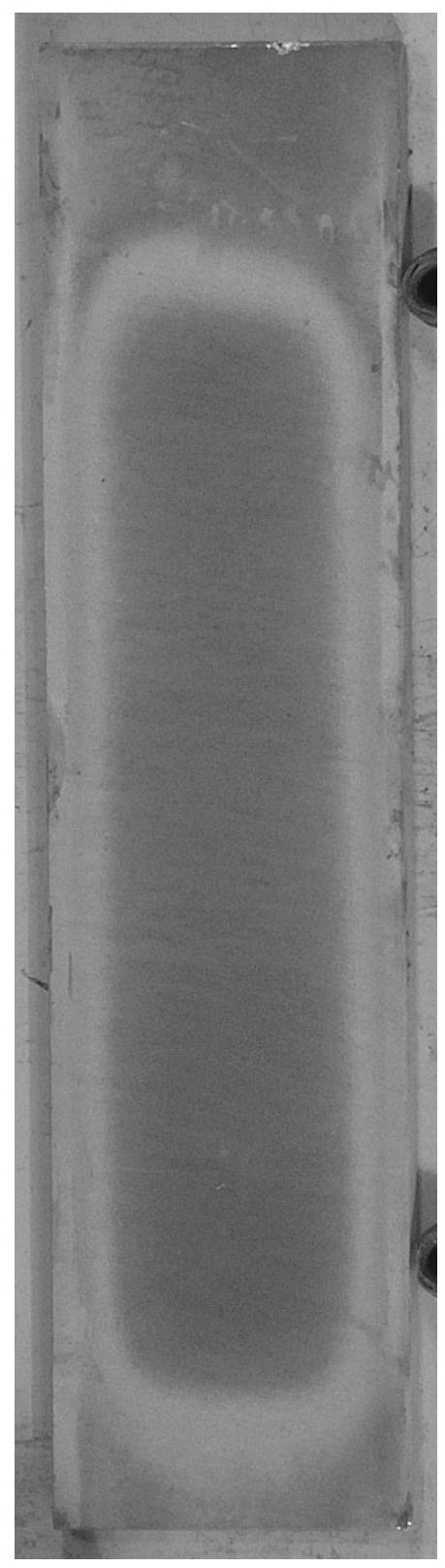

(b)

Figure 16. Visual inspection photographs of sample US16DM (a) front, and (b) back, which was irradiated in the $\mathrm{C} 2$ position.

Prior to irradiation, thickness measurements were made at 18 locations, as shown in Figure 17. The leftmost locations in the figure are at the bottom edge of the plate, in the margin outside the fuel region. Table 5 lists the results of those measurements. The mean thickness was $2.558 \mathrm{~mm}$ with a standard deviation of only $0.013 \mathrm{~mm}$ 


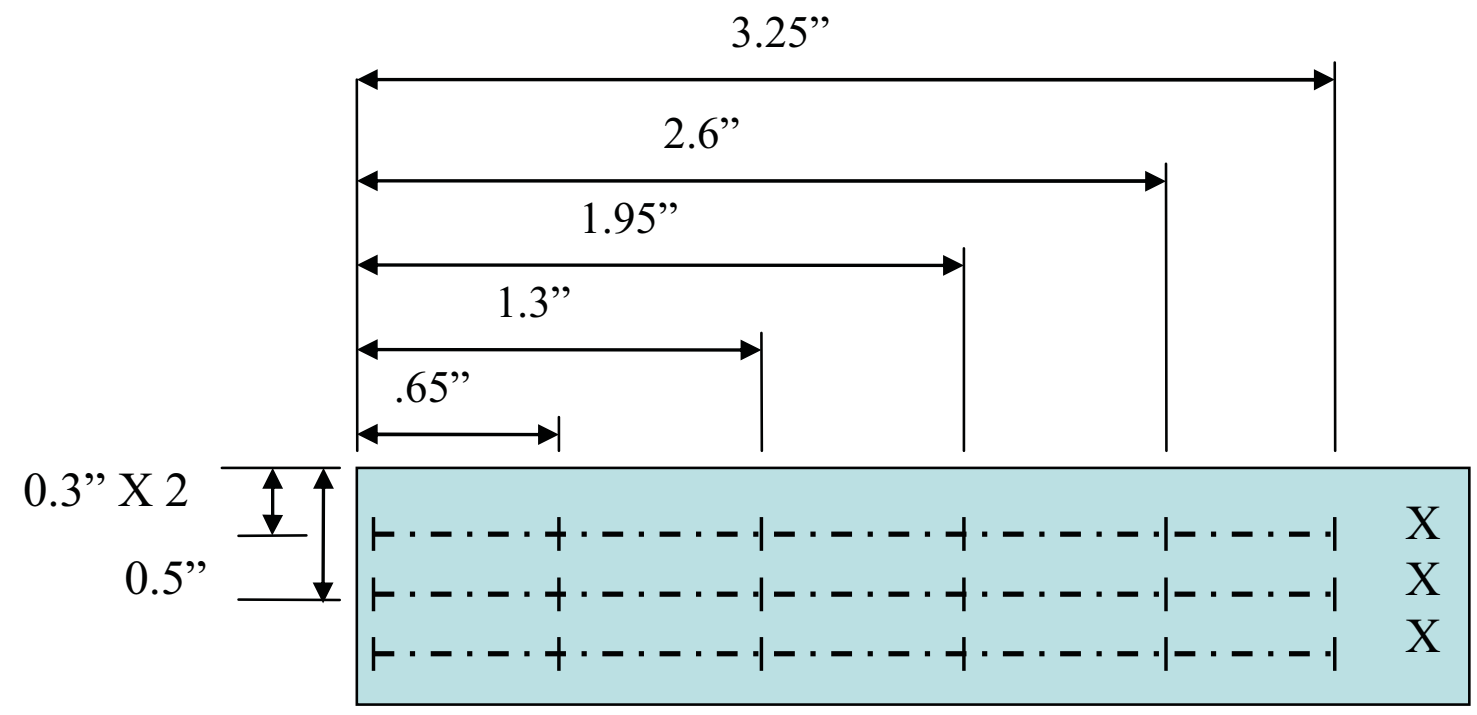

Figure 17. Locations of pre-irradiation thickness measurements on booster fuel mini-plate specimens.

Table 5. Pre-irradiation thickness measurements (mm) on specimen US16DM.

\begin{tabular}{r|rrrrrr}
\cline { 2 - 7 } & \multicolumn{6}{|c}{ From End (in) } \\
\hline From Edge (in) & Bottom & $\mathbf{0 . 6 5}$ & $\mathbf{1 . 3}$ & $\mathbf{1 . 9 5}$ & $\mathbf{2 . 6}$ & $\mathbf{3 . 2 5}$ \\
$\mathbf{0 . 3}$ & 2.5324 & 2.5603 & 2.5679 & 2.5654 & 2.5654 & 2.5476 \\
$\mathbf{0 . 5}$ & 2.5324 & 2.5527 & 2.5629 & 2.5679 & 2.5654 & 2.5679 \\
$\mathbf{0 . 8}$ & 2.5324 & 2.5603 & 2.5654 & 2.5705 & 2.5654 & 2.5629 \\
\hline
\end{tabular}

After irradiation, thickness measurements were made at 40 locations on each plate. These locations are located on a $4 \times 10$ node grid pattern over the fuel meat part of the plate. Table 6 gives the results of those measurements for sample US16DM shown in Figure 16. After irradiation, the mean thickness was $2.580 \mathrm{~mm}$ with a standard deviation of $0.021 \mathrm{~mm}$. Swelling values were acceptable for the very high fission densities experienced.

Table 6. Thickness measurement results (mm) for sample US16DM at the locations indicated.

\begin{tabular}{|c|c|c|c|c|c|}
\hline & \multicolumn{4}{|c|}{ Distance from Edge (inches) } \\
\hline & & 0.2 & 0.4 & 0.6 & 0.8 \\
\hline \multirow{10}{*}{ 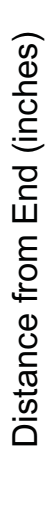 } & 0.55 & 2.522 & 2.543 & 2.551 & 2.541 \\
\hline & 0.872 & 2.558 & 2.606 & 2.614 & 2.588 \\
\hline & 1.194 & 2.564 & 2.582 & 2.593 & 2.583 \\
\hline & 1.517 & 2.565 & 2.579 & 2.584 & 2.572 \\
\hline & 1.839 & 2.569 & 2.584 & 2.587 & 2.576 \\
\hline & 2.161 & 2.573 & 2.584 & 2.595 & 2.579 \\
\hline & 2.483 & 2.568 & 2.588 & 2.604 & 2.588 \\
\hline & 2.806 & 2.56 & 2.592 & 2.602 & 2.583 \\
\hline & 3.128 & 2.562 & 2.616 & 2.604 & 2.582 \\
\hline & 3.45 & 2.56 & 2.614 & 2.616 & 2.579 \\
\hline
\end{tabular}


Gamma scans were made horizontally and vertically over the specimens to capture gradients in flux intensities. As irradiated, the samples had been oriented with the flat surface of each miniplate essentially parallel with a ray coming from the reactor center axis. Radial flux gradients away from the core centerline were clearly evident in the gamma scans as were axial flux gradients away from the core mid-plane, in the vertical direction. Radial variations were generally less than 10 percent over the sample width while axial variations were as much as 20 percent over each sample length. Samples away from the mid-plane registered lower gamma intensities than those closer to the mid-plane. Overall profiles were as expected.

Oxide thickness was measured at each of 9 locations on both the front and back of each plate. Measurements were made using a hand-held eddy current probe manufactured by HELMUT FISCHER model DeltaScope MP30 modified for hot cell use. Measurements were made at locations indicated in Figure 18. Measurement results are listed for each of the specimens in Table 7. Oxide layers were acceptable and uniform across the experiment.
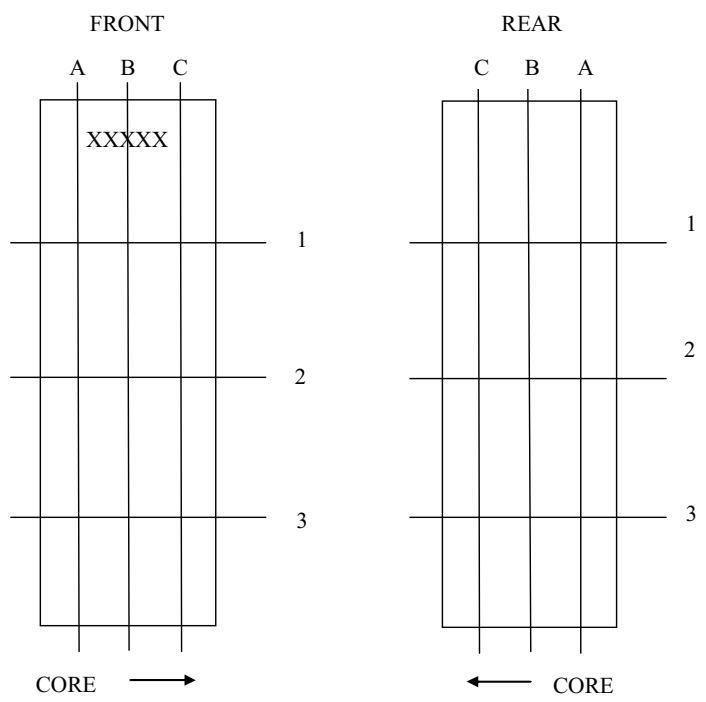

Figure 18. Locations for surface oxide measurements on the mini-plate specimens.

Table 7. Results of mini-plate surface oxide measurements. Thicknesses are in micrometers.

\begin{tabular}{|c|c|c|c|c|c|c|c|c|}
\hline Capsule & Plate ID & Count & Front-A & Front-B & Front-C & Back-A & Back-B & Back-C \\
\hline \multirow{10}{*}{ A } & \multirow{3}{*}{ US06CS } & 1 & 0.4 & 2.3 & 1.7 & 2.4 & 1.6 & 2.9 \\
\hline & & 2 & 1.5 & 3.6 & 5.3 & 3.5 & 4.0 & 5.0 \\
\hline & & 3 & 1.8 & 3.8 & 4.0 & 4.7 & 3.5 & 4.2 \\
\hline & & & & & & & & \\
\hline & \multirow{3}{*}{ US15DM } & 1 & 1.3 & 2.6 & 2.5 & 0.9 & 2.1 & 1.9 \\
\hline & & 2 & 1.7 & 3.4 & 2.8 & 1.4 & 1.6 & 3.2 \\
\hline & & 3 & 1.5 & 0.6 & 0.9 & 0.1 & 0.6 & 0.8 \\
\hline & & 1 & 88 & 82 & 1 & 52 & 87 & 71 \\
\hline & \multirow[t]{2}{*}{ US03HS } & $\frac{1}{2}$ & $\begin{array}{l}0.0 \\
10.1\end{array}$ & $\begin{array}{r}0.2 \\
14.1\end{array}$ & 15.9 & 9.5 & $\begin{array}{r}0.1 \\
12.4\end{array}$ & 12.8 \\
\hline & & 3 & 9.1 & 10.3 & 9.5 & 9.5 & 10.4 & 13.3 \\
\hline
\end{tabular}




\begin{tabular}{|c|c|c|c|c|c|c|c|c|}
\hline & \multirow{4}{*}{ US11GS } & & & & & & & \\
\hline & & 1 & 3.2 & 5.0 & 7.5 & 3.2 & 3.1 & 5.1 \\
\hline & & 2 & 8.7 & 8.1 & 12.0 & 8.0 & 7.7 & 10.3 \\
\hline & & 3 & 5.6 & 5.4 & 7.4 & 5.0 & 6.4 & 10.4 \\
\hline & & & & & & & & \\
\hline \multirow{15}{*}{ B } & \multirow{3}{*}{ USO4GS } & 1 & 3.7 & 6.4 & 6.8 & 7.0 & 8.1 & 17.0 \\
\hline & & 2 & 13.4 & 15.2 & 22.3 & 13.1 & 14.0 & 21.5 \\
\hline & & 3 & 12.6 & 12.2 & 19.7 & 4.2 & 5.8 & 7.0 \\
\hline & & & & & & & & \\
\hline & \multirow{3}{*}{ UN01ES } & 1 & 2.8 & 3.5 & 4.1 & 6.7 & 8.4 & 10.8 \\
\hline & & 2 & 9.6 & 12.3 & 17.1 & 11.0 & 13.7 & 20.0 \\
\hline & & 3 & 10.1 & 12.5 & 15.7 & 8.2 & 5.4 & 13.4 \\
\hline & & & & & & & & \\
\hline & \multirow{3}{*}{ US02FS } & 1 & 19.0 & 24.1 & 24.6 & 21.0 & 17.5 & 24.9 \\
\hline & & 2 & 23.5 & 29.2 & 30.8 & 27.8 & 30.0 & 28.1 \\
\hline & & 3 & 16.0 & 16.2 & 19.1 & 6.9 & 13.5 & 9.7 \\
\hline & & & & & & & & \\
\hline & \multirow{3}{*}{ UA01FS } & 1 & 17.6 & 14.1 & 14.1 & 15.9 & 15.0 & 21.0 \\
\hline & & 2 & 24.9 & 27.9 & 27.9 & 24.0 & 24.8 & 31.0 \\
\hline & & 3 & 11.1 & 19.8 & 19.8 & 15.3 & 15.3 & 17.9 \\
\hline & \multirow{4}{*}{ US07FS } & & & & & & & \\
\hline \multirow{15}{*}{$\mathrm{C}$} & & 1 & 16.0 & 21.0 & 22.6 & 10.3 & 11.3 & 8.1 \\
\hline & & 2 & 24.2 & 27.8 & 32.9 & 21.6 & 24.3 & 27.2 \\
\hline & & 3 & 18.6 & 15.5 & 19.2 & 17.3 & 18.7 & 22.6 \\
\hline & & & & & & & & \\
\hline & \multirow{3}{*}{ US16DM } & 1 & 13.2 & 14.6 & 17.8 & 13.9 & 16.8 & 20.7 \\
\hline & & 2 & 20.6 & 23.4 & 28.0 & 24.2 & 26.8 & 33.0 \\
\hline & & 3 & 13.5 & 15.3 & 16.8 & 13.2 & 16.5 & 23.2 \\
\hline & & & & & & & & \\
\hline & \multirow{3}{*}{ US08CS } & 1 & 18.9 & 17.4 & 12.1 & 12.8 & 14.1 & 14.3 \\
\hline & & 2 & 30.0 & 29.5 & 28.4 & 29.7 & 29.0 & 29.6 \\
\hline & & 3 & 17.4 & 18.3 & 20.7 & 17.0 & 24.2 & 19.5 \\
\hline & & & & & & & & \\
\hline & \multirow{3}{*}{ US14DS } & 1 & 10.1 & 10.7 & 9.8 & 20.7 & 16.4 & 20.8 \\
\hline & & 2 & 27.2 & 25.3 & 26.4 & 27.6 & 32.7 & 27.0 \\
\hline & & 3 & 23.2 & 21.0 & 22.2 & 17.2 & 20.3 & 15.3 \\
\hline & \multirow{4}{*}{ US09FS } & & & & & & & \\
\hline \multirow{11}{*}{$\mathrm{D}$} & & 1 & 9.4 & 9.6 & 7.5 & 9.5 & 7.9 & 6.3 \\
\hline & & 2 & 23.5 & 19.7 & 18.8 & 20.1 & 17.9 & 17.4 \\
\hline & & 3 & 15.6 & 15.5 & 13.2 & 12.3 & 11.4 & 11.6 \\
\hline & & & & & & & & \\
\hline & \multirow{3}{*}{ UN03ES } & 1 & 11.0 & 8.4 & 10.9 & 8.6 & 13.1 & 14.5 \\
\hline & & 2 & 11.4 & 12.0 & 15.7 & 13.2 & 13.0 & 15.6 \\
\hline & & 3 & 4.4 & 5.7 & 3.4 & 3.0 & 3.1 & 4.6 \\
\hline & & & & & & & & \\
\hline & \multirow{3}{*}{ US13GS } & 1 & 5.0 & 5.9 & 5.0 & 8.9 & 6.2 & 8.4 \\
\hline & & 2 & 11.6 & 9.7 & 10.5 & 9.9 & 8.9 & 9.4 \\
\hline & & 3 & 8.0 & 7.9 & 7.8 & 6.4 & 6.1 & 5.1 \\
\hline
\end{tabular}




\begin{tabular}{|l|l|r|r|r|r|r|r|r|}
\hline & \multirow{3}{*}{ US17GM } & 1 & 8.1 & 4.9 & 5.4 & 8.9 & 8.3 & 6.3 \\
\cline { 3 - 8 } & 2 & 10.3 & 10.5 & 10.1 & 14.2 & 10.8 & 9.4 \\
\cline { 3 - 8 } & 3 & 6.6 & 7.1 & 6.3 & 3.0 & 6.1 & 5.6 \\
\hline
\end{tabular}

Following the measurements for swelling and oxide thickness, samples were sectioned in metallographic mounts. Again, results were as expected. Figure 19 contains a montage of several higher resolution images of the section of sample US16DM. Higher resolution images appear in Figure 20. The mini-plates were oriented with the plate width dimension parallel to a ray from the reactor center. Hence, the edge of the plate closer to the center is the high-power edge and the one toward the outside of the core is the low-power edge.

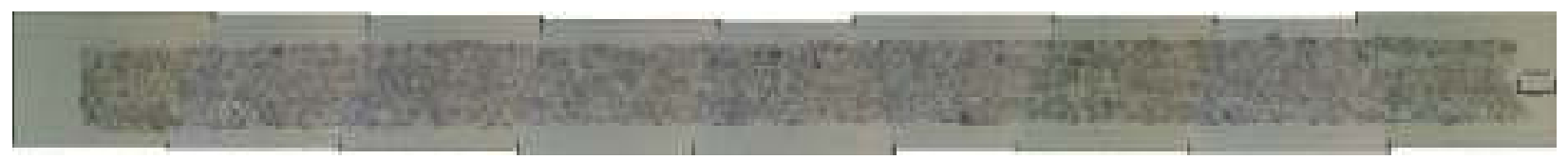

Figure 19. Metallographic montage of cross section images for sample US16DM.

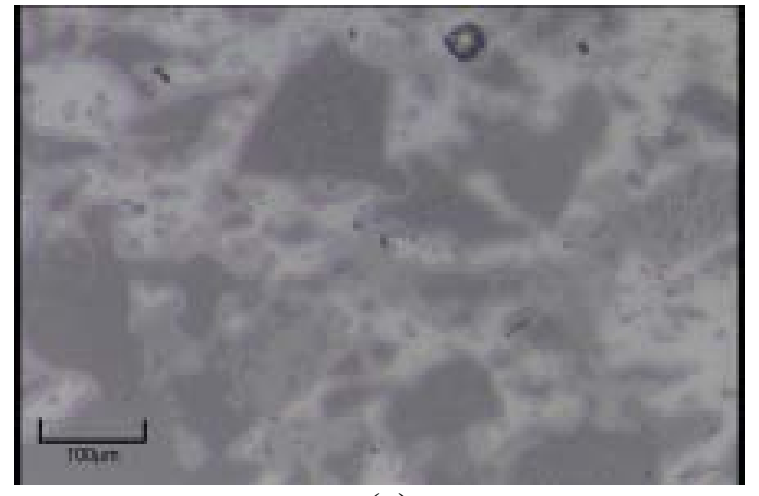

(a)

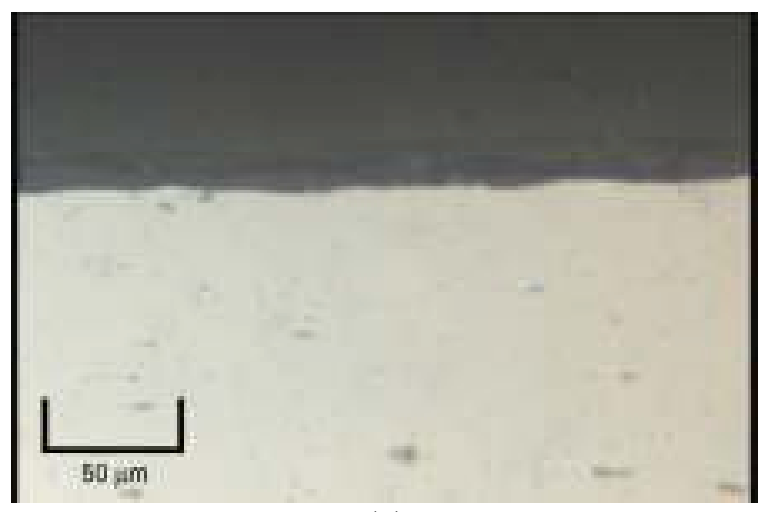

(c)

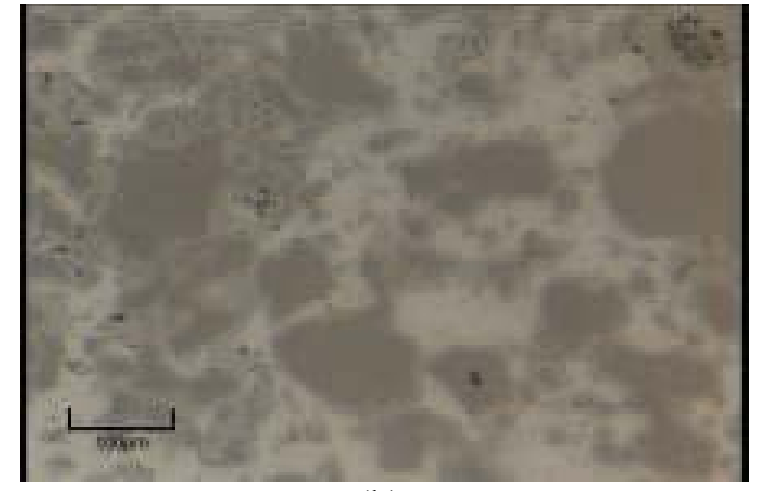

(b)

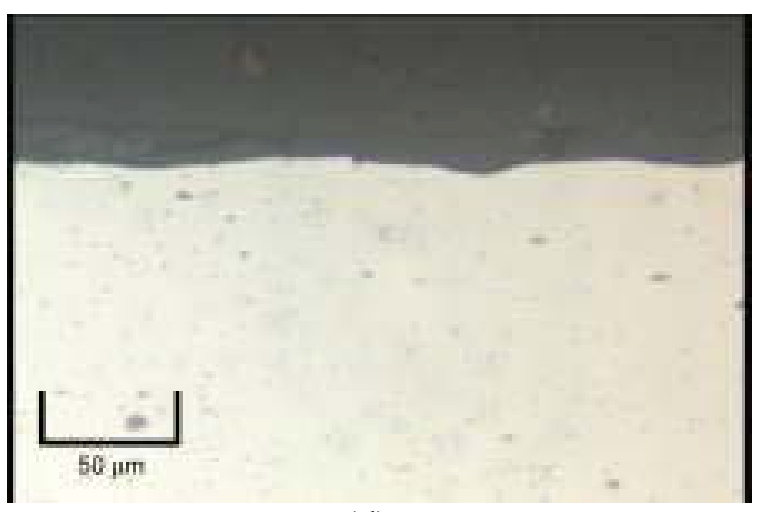

(d)

Figure 20. Metallographic images of specimen US16DM (a) fuel meat at low-power edge, (b) fuel meat at high-power edge, (c) oxide film interface at low-power edge, and (d) oxide film interface at high-power edge. 
Figures 21 and 22 are similar images for sample UA01FS. These are representative of all the metallographic results.

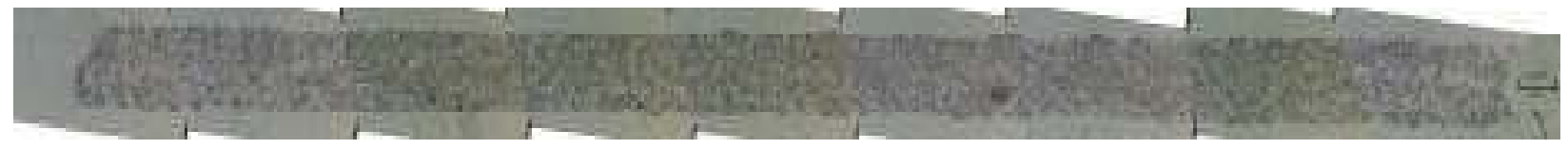

Figure 21. Metallographic montage of cross section images for sample UA01FS.

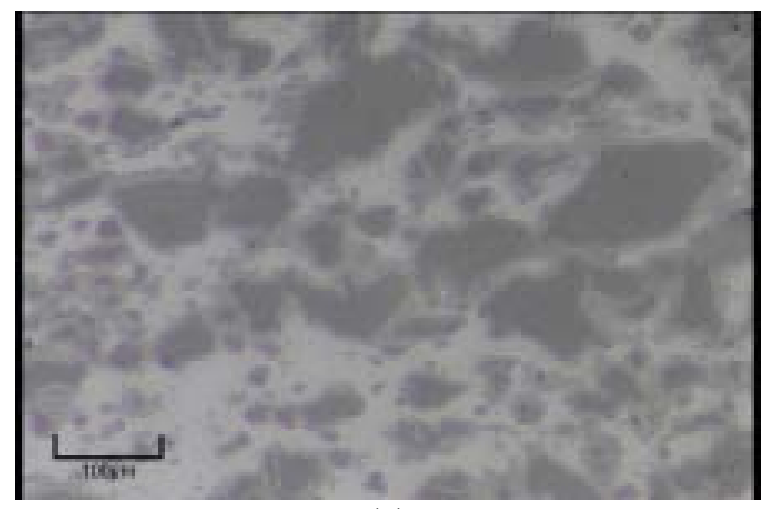

(a)

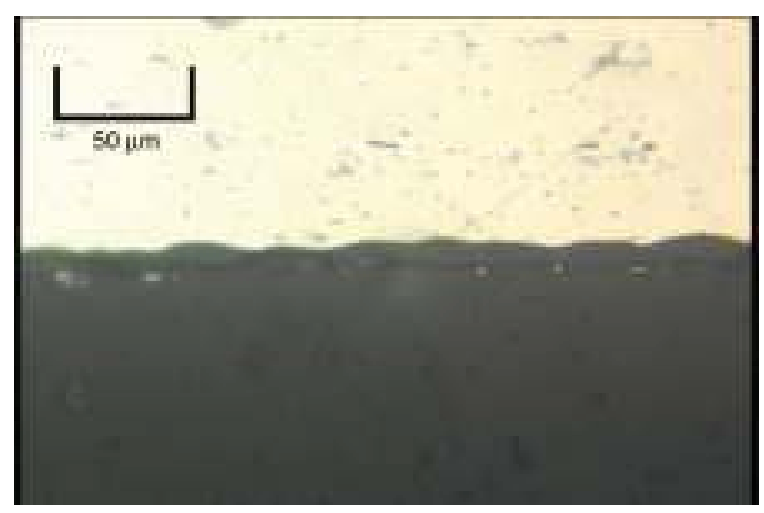

(c)

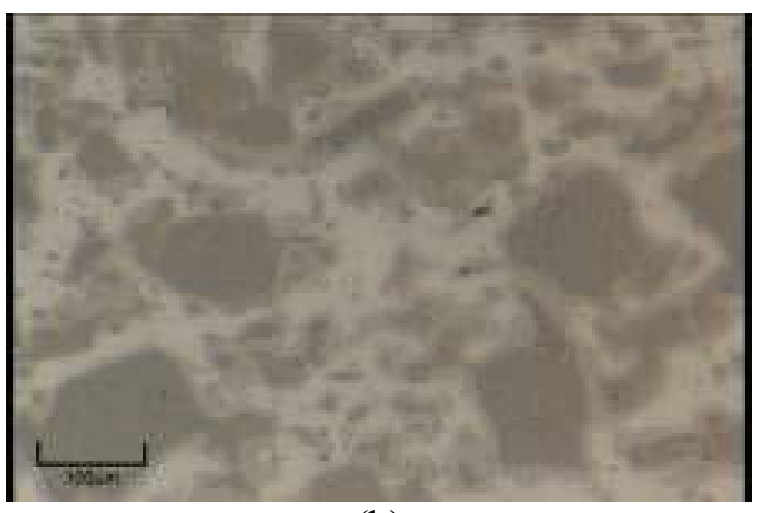

(b)

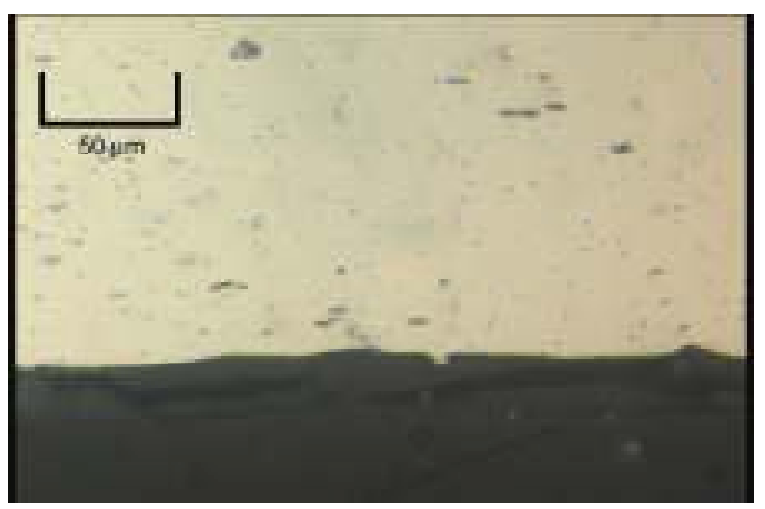

(d)

Figure 22. Metallographic images of specimen UA01FS (a) fuel meat at low-power edge, (b) fuel meat at high-power edge, (c) oxide film interface at low-power edge, and (d) oxide film interface at high-power edge.

The montages of Figures 19 and 21, though not complete for the cladding, show that there was no corrosion of the cladding down to the fuel layers. Further, there was no gross swelling of the fuel meat. In Figures 20 and 22 (c) and (d), the oxide layer is dark and the cladding is bright. It is clear that the oxide layer is intact and that corrosion of the oxide layer was not an issue. In the Figures 20 and 22 (a) and (b), there are aluminum silicide zones around the fuel particles, and some fuel particles appear to be $\mathrm{U}_{3} \mathrm{Si}$ as opposed to $\mathrm{U}_{3} \mathrm{Si}_{2}$. This is a consequence of the aluminum-silicon reaction depleting the uranium silicide fuel grains of silicon. This reaction was expected and is typical for the high temperatures at which these specimens were irradiated. It should not be a problem for booster fuel performance. More complete results of the PIE of the GTL-1/BFFL mini-plates are included in Ref. [17]. The conclusion from the postirradiation 
examination of the GTL-1 miniplates is that both Al-6061 cladding corrosion and $\mathrm{U}_{3} \mathrm{Si}_{2}$ fuel stability under the high heat flux and high temperature conditions predicted of BFFL booster fuel plate is acceptable; thus, the technical feasibility of the booster fuel design from the perspective of irradiation performance is established.

\subsection{ATR Safety Basis Review}

A fourth activity planned but not completed was a review of the consequences of operating the ATR with one of the corner lobes at the high power required for the BFFL and associated impacts on plant safety and reliability.

\subsection{Technical Coordination Committee}

Members of the TCC were selected from academia, national laboratories, and industry; and each brings a varied prospective to the committee. Members of the TCC have years of experience related to fuel design, reactor operations, fuel manufacturing, and fuel qualification.

Members of the TCC are: Dr. Todd Allen, University of Wisconsin-Madison, Chairman; Dr. James Tulenko, University of Florida; Mr. John Sease, ORNL; Mr. Charles McKibben, University of Missouri, Mr. John Schmucker, BWXT ${ }^{1}$; Dr. James Snelgrove, ANL; Dr. Madeline Feltus, DOE-NE (ex officio); and the late Dr. Nathan Chipman, INL (ex officio). The makeup of the committee was to ensure a complex-wide range of expertise was applied to issues identified as the project was developed.

The TCC concentrated its reviews on the need for uranium silicide fuel as the booster fuel, physical designs of the booster fuel, neutronic and thermal-hydraulic behavior of the booster fuel, and the fuel qualification plan.

As there is no prescribed method to qualify a new fuel for use in the ATR, the TCC was asked specifically to comment on the staged approach to fuel qualification. In that approach, the project irradiated the mini-plates to examine damage and corrosion issues, and the plan was to irradiate of a single booster fuel plate to examine curvature and manufacturing issues, and then the full booster fuel assembly to demonstrate system performance. The irradiation testing of the miniplates as well as the overall booster fuel qualification plan were reviewed and approved by the TCC.

\subsection{System Cost}

A detailed cost estimate was prepared for the first GTL configuration, with the gas systems shown in Figure 9, that resulted in a total project cost rounded to $\$ 84 \mathrm{M}$. Uncertainties and project delays since that estimate led to a more practical cost range of $\$ 80-100 \mathrm{M}$. That detailed GTL cost estimate was the point of departure for preparing a revised estimate for the revised configuration, now called BFFL, total system cost. The bottom-line comparison of the BFFL cost with the GTL cost shows a reduction of approximately $\$ 25-30 \mathrm{M}$ by changing to the BFFL configuration. Even with irradiation charges for single plate irradiation and first-operation demonstration tests of more than $\$ 11 \mathrm{M}$ included, the updated project cost was estimated at

\footnotetext{
${ }^{1}$ Mr. Schmucker's participation in the TCC ended when it was necessary to terminate the booster fuel fabrication assessment activity.
} 
between $\$ 50 \mathrm{M}$ and $\$ 75 \mathrm{M}$. The estimated cost with a $25 \%$ contingency was $\$ 63.4 \mathrm{M}$. The $\$ 50 \mathrm{M}$ figure is a nominal cost without contingency and the higher $\$ 75 \mathrm{M}$ figure is with about $50 \%$ contingency, which would not be unreasonable for this stage of concept development.

Operating funding to date has included

FY-04 \$0.5M (DOE-NE)

FY-05 \$4.2M (DOE-NE) + \$2.0M (DOE-NR)

FY-06 \$2.0M (DOE-NE)

FY-07 \$1.2M (DOE-NE)

Capital funding has been allocated but unused pending CD-1 approval and since rescinded.

The program plan initially called for system availability in 4 years from project start. Given the need to develop and qualify booster fuel, the estimated time required was increased to 7 years. If the distributed thermal neutron absorber is fully developed, with included irradiation testing, the overall schedule would not change much from the 7 year estimate.

\subsection{Conclusion}

The GTL/BFFL was conceived as a means of allowing fast-spectrum irradiation testing to be performed in the near term, before a domestic fast-flux research reactor could be built. Though expensive, it is far less costly than the construction of a new reactor and would be available far sooner. It could fill the gap in irradiation capability for several years while a new test reactor is being built.

The GTL/BFFL would be capable of providing a fast fission spectrum approximation with a fast flux of $10^{15} \mathrm{n} / \mathrm{cm}^{2}$.s and a fast-to-thermal neutron flux ratio of 15 or better, possibly up to 30 . Though about a factor of 3 lower in flux intensity than could be achieved in a fast-flux reactor, if located in the ATR, the GTL/BFFL would have reasonably large test volumes in which irradiations of advanced reactor fuels and materials could be undertaken.

\section{References}

1. Department of Energy, Office of Nuclear Energy, Science and Technology, June 28, 2004, Justification of Mission Need for the Gas Test Loop, INEEL/EXT-04-02018, Idaho National Engineering and Environmental Laboratory, Idaho Falls, Idaho.

2. G. R. Longhurst, S. T. Khericha, and J. L. Jones, September 2004, as Test Loop Technical and Functional Requirements, INEEL/EXT-04-02273, Idaho National Engineering and Environmental Laboratory, Idaho Falls, Idaho.

3. W. F. Skerjanc and G. R. Longhurst, July 2005, Gas Test Loop Facilities Alternatives Assessment Report, INL/EXT-06-00263 Rev. 1, Idaho National Laboratory, Idaho Falls, Idaho.

4. Gas Test Loop Project Staff, October 2004, Gas Test Loop Conceptual Design: 70\% Progress Report, INEEL/EXT-04-02450, Idaho National Engineering and Environmental Laboratory, Idaho Falls, Idaho. 
5. Gas Test Loop Project Staff, March 2005, Gas Test Loop Conceptual Design: 30\% Progress Report, INL/EXT-05-00051, Idaho National Laboratory, Idaho Falls, Idaho.

6. Gas Test Loop Project Staff, September 13, 2005, Gas Test Loop Conceptual Design Report, Draft, INL/EXT-05-00261, Rev B, Idaho National Laboratory, Idaho Falls, Idaho.

7. Gas Test Loop Project Staff, September 13, 2005, Gas Test loop Critical Decision 1 A Submittal, Idaho National Engineering and Environmental Laboratory, Idaho Falls, Idaho.

8. G. R. Longhurst, D. Post Guillen, J. R. Parry, D. L. Porter, and B. W. Wallace, August 2007, Boosted Fast Flux Loop Alternative Cooling Assessment, INL/EXT-07-12994 Rev. 0, Idaho National Laboratory, Idaho Falls, ID.

9. Department of Energy, Office of Nuclear Energy, June 12, 2007, OMB Circular No. A-11 (2007), FY-09 OMB exhibit 300, Capital Asset Plan and Business Case Summary, Part I Summary Information and Justification, Project ID -06-ID-03, "Fast Neutron Test Capability, formerly Gas Test Loop".

10. G. R. Longhurst and S. T. Khericha, July 2005, Gas Test Loop Technical and Functional Requirements, INEEL/EXT-04-02273 Rev A, Idaho National Laboratory, Idaho Falls, Idaho.

11. A. G. Croff, 1980, "ORIGEN2 - A Revised and Updated Version of the Oak Ridge Generation and Depletion Code," ORNL-5G21, Oak Ridge National Laboratory, Oak Ridge, Tennessee.

12. Upgraded Final Safety Analysis Report (UFSAR) Chapter 4 - Reactor, SAR-153-4, Rev. 13, April 29, 2009, Idaho National Engineering and Environmental Laboratory, Idaho Falls, Idaho.

13. J. F. Briesmeister (ed.), "MCNP - A general Monte Carlo N-Particle Transport Code, Version-4C,” LA-13709-M, Los Alamos National Laboratory (March 2000).

14. F. W. Walker, J. R. Parrington, and F. Feiner, 1989, Nuclides and Isotopes, $14^{\text {th }}$ Edition, General Electric Company Nuclear Energy Operations, San Jose, California.

15. Gas Test Loop Hydraulic Testing Staff, September 2006, Gas Test Loop Booster Fuel Hydraulic Testing, INL/EXT-06-11751, Idaho National Laboratory, Idaho Falls, Idaho.

16. Donna Post Guillen and Mark J. Russell, "Estimation of Critical Flow Velocity for Collapse of Gas Test Loop Booster Fuel Assembly," American Society of Mechanical Engineers, Proceedings of ICONE14 International Conference on Nuclear Engineering, Miami, FL, 17-20 July 2006, Paper ICONE14-89130.

17. Adam. B. Robinson, July 2009, “GTL Non-Destructive Examination Results,” ECAR-677, Idaho National Laboratory, Idaho Falls, Idaho. 